\title{
THE EFFECT OF PRELIMINARY HEAT TREATMENT UPON THE DRYING OF CLAYS
}

\author{
By A. V. Bleininger
}

CONTENTS

Page

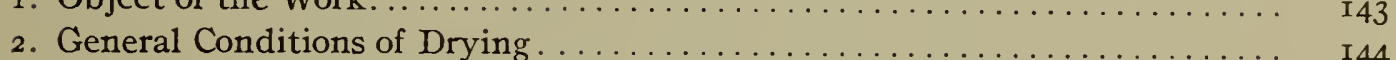

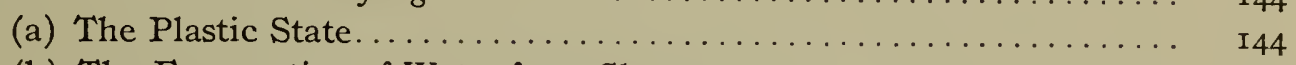

(b) The Evaporation of Water from Clay ................... I 47

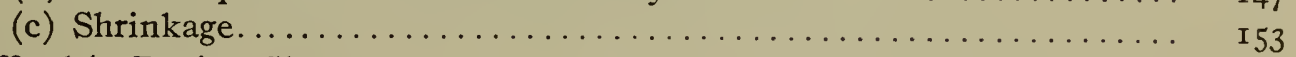

3. Difficultly Drying Clays................................ ${ }^{{ }_{1}} 57$

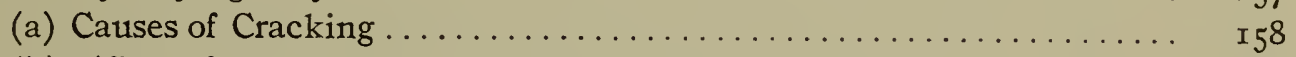

(b) Effect of Non-Plastic Materials ..................... ${ }_{5} 8$

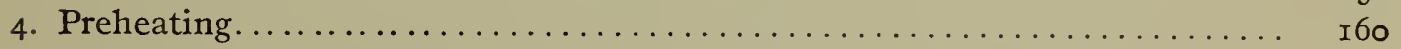

(a) The Clays used in the Experiments................... 160

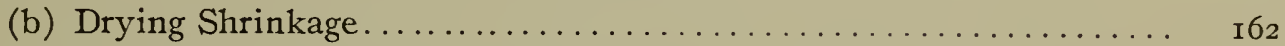

(c) Mechanical Analysis............................. I64

(d) Viscous Condition of Clay Suspensions in Water............. I68

5. The Preheating Treatment............................... $\quad{ }_{77}$

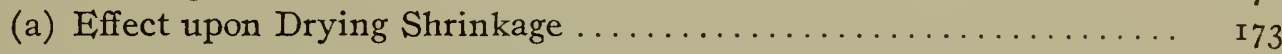

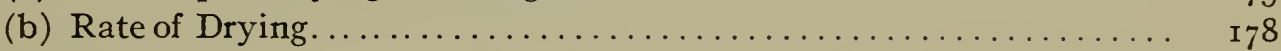

6. The Practical Effect of Preheating....................... I79

7. The Cause of the Improvement in the Drying Behavior Due to Preheating. . $\quad$ i 83

8. The Effect of Preheating upon the Manufacture of Clay Products........ igI

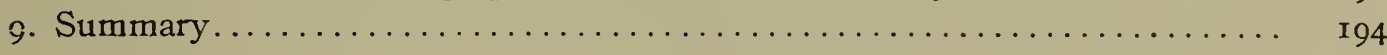

\section{OBJECT OF THE WORK}

This investigation has been undertaken for the purpose of looking into the possibility of using the excessively plastic clays, which on drying by any commercial method show great losses due to cracking and checking, by subjecting them in the crude state to a preliminary heat treatment before working them by the usual methods. There are, especially in a number of the Western States and on public lands, many clays of this sticky, heavy type which 
resist all ordinary modes of preparation. To this class of materials belong the so-called joint and swamp clays of the glacial regions of Ohio, Indiana, Illinois, Wisconsin, Minnesota, North Dakota, and other States and Territories.

In order to bring out clearly the various effects of such a preliminary treatment, extensive laboratory experiments have been made on small and large samples of widely differing plastic clays. Preheating, rather than other possible treatments, such as the admixture of sand or sandy clay or the addition of salts like sodium carbonate and sodium silicate, has been chosen, since the mixture with nonplastic materials like sand presupposes the presence of the latter within a reasonable distance, which frequently is not the case; on the other hand, the incorporation of soluble salts even in very small amounts may give rise to the appearance of disagreeable efflorescence on the surface of the ware. Still other means of dealing with this problem, such as the exposure of the dug clay to freezing during the winter or drying out in the summer, are not always practicable nor effective. Furthermore, mechanical drying has become a well-developed feature of many industrial processes, and its cost is in part compensated by the resulting regularity of the manufacturing process, the possibility of eliminating objectionable mineral detritus like gravel, lime pebbles, etc., and other desirable features.

\section{GENERAL CONDITIONS OF DRYING}

(a) The Plastic State.-The use of clay in the arts depends upon its plasticity, the property of retaining any shape into which it is molded, supplemented by its quality of hardening to a stonelike mass when dried and burnt. The cause of plasticity has been made the subject of elaborate discussions, ${ }^{1}$ but as yet no exact explanation has been found for it. The most convincing experimental researches ${ }^{2}$ ascribe the phenomenon of plasticity to the presence of colloidal substances which behave in many respects

${ }^{1}$ For an excellent summary, see Heinrich Ries: Clays, Their Propertics and Occurrence.

${ }^{2}$ Schloesing: Compt. Rend. 79, pp. 376-80, 473-77, r874. Van Bemmelen, Zs. f. anorg. Chemie, 18, I4-36, I8, 98-146. Cushman, A. S., The Colloid Theory of Plasticity, Trans. Am. Ceramic Soc., 6, 65-78; On the cause of the cementing value of rock powders and the plasticity of clays, J. Am. Chem. Soc. 25, 45I-468; Ashley, H. E., Bull. 388, U. S. Geological Survey. 
similarly to the typical colloids, such as silicic acid, ferric hydroxide, aluminum hydroxide, gelatine, glue, etc., in that they show the phenomena of hydrolysis, osmosis, adsorption, the ability to change from the gel to the sol form and vice versa in the presence of an excess of positive or negative ions, the property of shrinking in apparent volume down to a certain point proportionally to the loss of water, and the character of their dehydration and vapor tension curves.

This view therefore appears to offer the most satisfactory basis for explaining the properties of clays and seems to reconcile some of the older theories which have been proposed.

We may then assume that the cementing substance of clays is represented by some colloid, not necessarily of a definite chemical composition nor always of the same physical character, which possesses a more or less marked micellean structure in which water is held in the free and absorbed condition. Owing to the fact that clays are of different origins and are subjected to various modifying conditions during and after deposition, it is very probable that they are made up of colloidal substances, which vary widely as regards their physical structure. Thus the clay substance of the light burning, plastic clays is bound to differ considerably from that of the red burning surface clays and shales, not only in amount, but in character as well. Again, in many clays, especially those of primary origin, the transition of the crystalline matter to the colloidal condition still goes on, due to weathering and other agencies. This applies particularly to materials of the kaolin type. In other types the colloidal clay substance, has been in part "set" by certain geological conditions, though not irreversibly. In these a close and dense structure prevails which does not absorb water until the latter is forced into the pores by grinding and pugging. Clays of this type therefore show but a feeble initial plasticity, but become workable by energetic mechanical treatment. Fire clays and shales are especially apt to show this kind of behavior.

It seems to be a fact, however, that plasticity as measured by the ability of the clay to be molded, and to flow through dies, is dependent upon the development of this water-saturated micellean structure. 
Equally important with the degree to which this condition of the cementing substance is developed is the amount and character of the nonplastic constituents of the clay which affect the plasticity as well as the resulting density of the clay body. This inert mineral matter, consisting of grains of quartz, feldspar, mica, limestone, pyrites, augite, hornblende, etc., not only dilutes the plastic clay substance, but by virtue of its granulometric composition, becomes a prominent factor in determining the resulting plasticity, drying shrinkage, ease of drying, and final density.

Since it is necessary to assume that each grain of nonplastic material be surrounded by an envelope of plastic substance, it is readily seen that the extent of the surface exposed by these particles is of great importance in regard to the plasticity and capillary structure.

Considering the subject theoretically and assuming that the crystalline grains are spherical in shape and fill a certain unit volume as compactly as possible, it can easily be shown that the total pore space remains constant at 30.3 per cent of the total volume, but that the surface exposed by the grains varies. If, for instance, the size of the particles were reduced from a diameter of $0.75 \mathrm{~mm}$ to $0.25 \mathrm{~mm}$, the total surface exposed under the above conditions would be three times as great as before. On assuming a reduction in size from $0.75 \mathrm{~mm}$ to $0.125 \mathrm{~mm}$, the surface would become six times as large. Or, speaking more generally, the surface exposed by different sizes of grain would be inversely proportional to the diameter. The surface of compactly arranged spherical particles in unit volume would vary as $4.1845(\mathrm{I} \div d)$, i. e., proportionally to the product of a constant and the reciprocal of the diameter.

Assuming that each particle must receive an envelope of plastic matter of uniform thickness, it is evident that the smaller grains would require a larger amount of this material than the particles of greater diameter. It is conceivable, therefore, that a definite volume of clay might prove insufficient to coat a large number of very fine grains, while the same quantity would be ample for an equivalent volume of larger, nonplastic particles. In the latter case, therefore, we should expect to find greater mobility of the mass as a whole, owing to the thicker enveloping layers which are 
made possible, i. e., the larger grains reduce the plasticity of the clay less than the finer. By analogy it appears, then, that the tensile strength of the clay would be the greater the larger the average size of the granular matter, provided the total amount is kept within proper limits.

If the nonplastic particles are not uniform in size, it is evident that the pore space between the granular skeleton is decreased and it is possible to assume a combination which will result in maximum density. Of two sands mixed with the same weight of clay, the one producing the smaller volume of clay-sand mixture will show the greater density. The granulometric relations holding between the various sizes of granular matter in clay are similar to those applying to cements, as shown by the experiments of Feret, ${ }^{3}$ although, however, there are certain differences inherent in the nature of clay.

It is seen, hence, that not only the amount and character of the colloidal clay matter, but also the amount and sizing of the nonplastic constituents govern the resulting plasticity. In addition, other factors are bound to be of more or less influence, such as the shape of the nonplastic particles, the presence of organic matter, various salts, bases, or acids.

(b) The Evaporation of Water from Clay.-In making up dry clay with water to form a plastic mass which may be shaped and molded, the resulting volume is somewhat greater than the sum of the volumes of clay and water. In this condition the clay particles, both plastic and granular, are surrounded on all sides by a film of water, while small pools or drops fill the cavities and pores between the grains. A tortuous system of capillaries is thus established which are wider in some places and narrower in others. When placed in an atmosphere saturated with moisture, equilibrium conditions are reached when no flow of water whatever takes place in these minute channels. As soon as the humidity is lowered, however, evaporation begins to take place on the surface, and every particle of water thus removed must be replaced through the capillary channels from the interior. The rapidity of this movement depends upon the structure of the clay-i. e., whether the capillaries are fine and intricate or coarse and short-

${ }^{3}$ Bull. de la Societe d'Encouragement, 2, p. I604; 1897. 
and upon the temperature and humidity of the outside air. Open structure, high temperature, and low humidity result in maximum capillary flow and vice versa. Since the spongelike colloidal matter with its immense surface and fine pores offers the greatest resistance to the passage of water, it is obvious that in highly plastic clays the movement of the water through the capillaries must be very slow, it having been estimated that the resistance to this flow is inversely proportional to the fourth power of the diameter of the channels. The capillary flow continues to grow weaker until the films become very thin and finally break altogether. ${ }^{4}$ The water remaining within the colloidal interstices and within the pores in isolated films is expelled with increasing difficulty, and, owing to its low vapor pressure, requires a high temperature for its complete expulsion.

Considering now the drying of clay from the experimental standpoint, the relation between shrinkage and loss of water during this process might be examined in a specific instance. The curves of figure I represent the linear shrinkage of a clay sphere in terms of the diameter in the dry state and the loss in weight expressed in per cent of the dry weight plotted against the time of drying in hours. ${ }^{5}$ The sphere was $7.1 \mathrm{I} \mathrm{cm}$ in diameter in the wet state and was carried through the drying stage in an oven maintained at a constant temperature of $60^{\circ} \mathrm{C}$. When a loss in weight was no longer observed, the temperature was raised to $120^{\circ}$, and finally to $200^{\circ}$. In each case the same temperature was maintained until the weight was constant. It is noted that down to a certain point the rate of shrinkage is proportional to the rate of the loss in weight, then the shrinkage becomes less than the loss of water, and finally it ceases, while the clay continues to evaporate water. The point at which shrinkage no longer takes place and where the clay grains are supposed to come in contact with each other is used to discriminate between two kinds of water. On drawing through this point a line parallel to the abscissa, the water lost above it represents the shrinkage and that below it the so-called pore water. Neither term is rigidly exact, since in some materials, especially

${ }^{4}$ Studies on the Movement of Soil Moisture, E. Buckingham, Bureau of Soils, Bull. No. 38 , p. 4 r.

${ }^{5}$ E. F. Lines, Note on the Drying of Clays, Trans. Am. Ceram. Soc., 10, p. I46. 
ILINEAR SHRINKAGE IN TERMS OF DRY DIAMETER

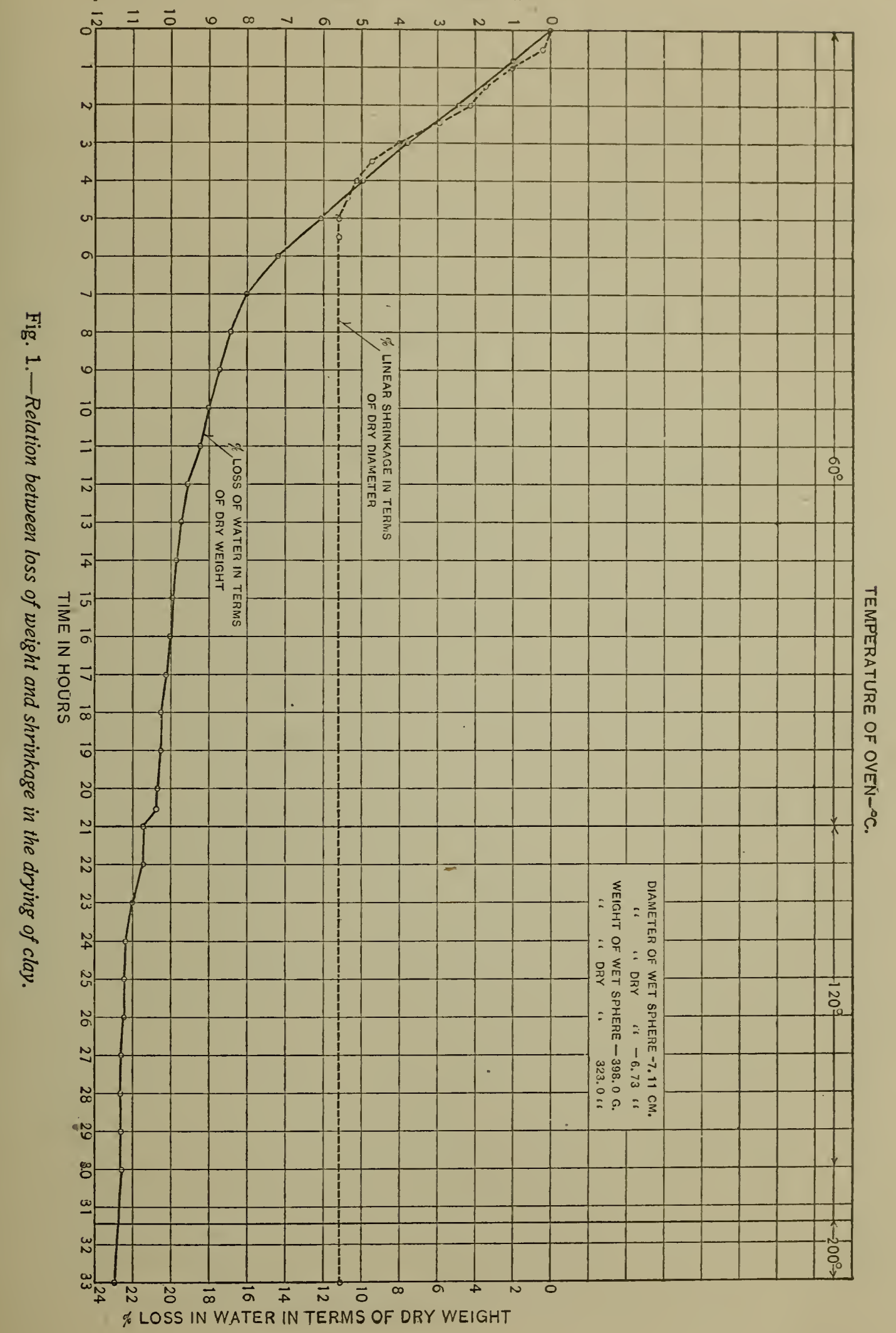


of the porous, feebly plastic type, the first loss in water is not necessarily equivalent to the shrinkage, and again the pore water includes also the adsorbed water and the water of imbibition.

The loss of water continues at a decreasingly slower rate until the weight is constant at the given temperature. Upon raising the temperature more water is expelled and this continues until finally the last residual portion is set free. The decreasing rate of the water loss is evidently due to the decreased capillary conductivity ${ }^{6}$ brought about by the reduction in the number of the capillary paths, the effect of surface tension and adsorption phenomena and with them the decrease in vapor pressure.

Upon bringing clay dried at atmospheric temperature again in contact with water the latter will at once be absorbed and the air within the network of capillaries expelled with the evolution of heat. The colloidal matter will swell in taking up the water so that not only the pores of the clay mass become filled, but a certain amount of the water is absorbed into the micellean structure. Clay invariably takes up water more readily in the dry than in the moist condition.

The water of the clay, as may be inferred from the fact that its vapor tension constantly becomes smaller, is by no means expelled completely when the specimen has reached the "bone-dry" condition at the temperatures of the commercial dryers. According to the nature of the clay and its structure more or less mechanical moisture remains which is given off only at higher temperatures. This so-called hygroscopic water which is held so tenaciously usually remains to be driven off in the kiln. It is evident therefore that this moisture is readily absorbed by dry clay from the air. In Table $I$ the results of drying 12 clays at temperatures from $60^{\circ}-200^{\circ} \mathrm{C}$ are shown; at each temperature the drying was continued until the weight became constant.

The increase in volume on the addition of water to dried clay is practically equal to its previous shrinkage on drying, provided the material has not been subjected to a higher temperature while in the dry state. If this has been the case the amount of water again taken up and the increase in volume will be distinctly less, and this is the more pronounced the higher the heating has been carried.

${ }^{6}$ Edgar Buckingham, Bull. $3^{8}$, Bureau of Soils, p. 4.3. 


\section{TABLE I}

Loss in Dry Weight on Heating

In per cent of the dry weight

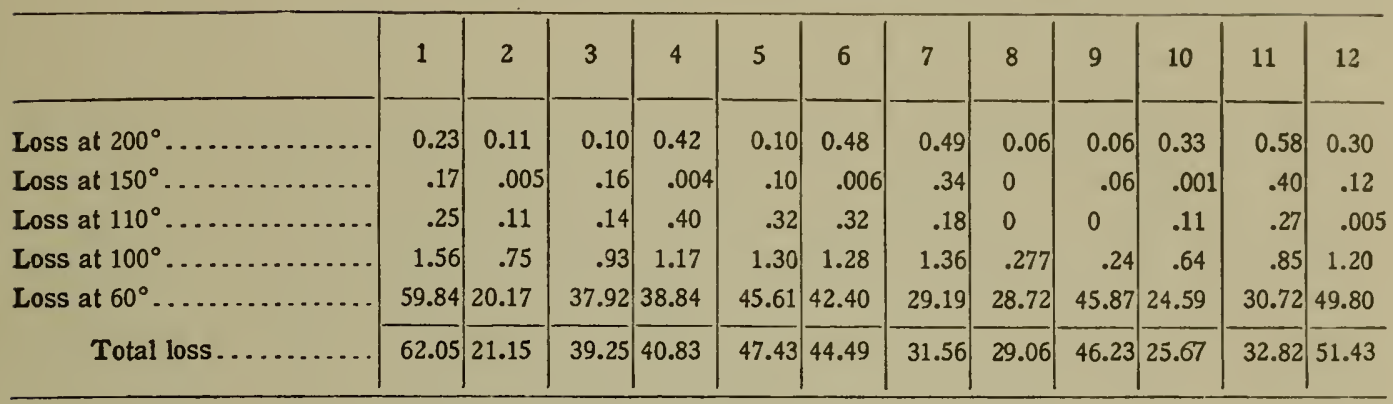

This is in accord with the results obtained by Van Bemmelen ${ }^{7}$ with silicic acid gels in which he noted a distinct lag in the absorption of water on rehydration. He found that at first the liquid between the pores of this colloidal material left at a rate corresponding to the evaporation of free water. This was found to hold true for a water content of from I 20-I 25 molecules.

Below this point the liquid within the micellean interstices evaporates at a continually slower rate owing to the narrowing of the capillaries. Also the vapor tension of the colloid decreases steadily, corresponding to the decrease in the content of absorbed liquid. At the same time constant changes occur in the physical condition of the substance which are slow at ordinary but accelerated at higher temperatures.

Van Bemmelen studied the inversion points by placing the silicic acid gels into desiccators containing 36 concentrations of sulphuric acid and hence corresponding to 36 aqueous tensions. He found several inversion points in the resulting dehydration curve. First, the substance becomes dull and fluorescent, then white like porcelain, and finally opaque white, like chalk, without gloss. This inversion changes the dehydration curve, since for a distance it runs parallel to the abscissa. The capacity to hold water then decreases more rapidly than before the inversion point. On continuing the dehydration still further the dimness disappears just as it appeared. The gel becomes porcelainlike, of bluish

${ }^{7}$ Zs. f. anorg. Chem. I8, I4-36; I8, 98-146;20, I85-2II. 
fluorescence, and finally as clear as glass, remaining thus until the final dehydration. Also, when the gel is at once exposed to higher aqueous tensions, after the inversion, it becomes gradually homogeneous and clear as glass. These inversions may be repeated, and they are hence reversible under certain conditions. It is evident therefore that certain changes occur in the micellean structure of the colloid at these inversion points forming new coagulations which disturb the continuity of the dehydration curve.

By taking now the silicic acid pats which have been carried on to the lowest aqueous tension (most concentrated sulphuric acid), and placing them in the desiccators containing the more dilute sulphuric acid solutions rehydration takes place. Van Bemmelen in again plotting the molecules of water at each stage against the aqueous tension then found that the dehydration curve was not reproduced, but that a distinct lag was observed analogous to hysteresis-i. e., while a certain aqueous tension in the case of the fresh silicic acid corresponded to a certain amount of water, the same tension in the rehydrated substance was equivalent to a smaller amount of water.

While a homogeneous substance like silicic acid is not strictly comparable to a heterogeneous mixture like clay, certain observations bearing on the one might be utilized in connection with . the other. The question which naturally arises is to what extent the plasticity of clays and its related phenomena, such as shrinkage, are reversible on heating clays up to temperatures still considerably below the dehydration point at which practically all clays lose their working quality completely. It has generally been understood that, up to the temperature at which the combined water is expelled, the plasticity and water absorption are to a large extent reversible; that is, the clays are able to resume a large share of their original plasticity. On the other hand it has been realized that a certain lag is observable since in pottery work it has been found that the dried ware which is again returned to the plastic state does not possess the same working quality on the jigger that it possessed originally. Whether on sufficient working and aging the clays would resume their initial plasticity is an open question, though it would seem very likely that this would be the case as far as the usual dried clay is concerned. 
(c) Shrinkage.-In a general way the conditions governing the rate of drying of clays have been indicated. As has been pointed out the true volume of the dry clay plus the volume of water required to produce plasticity is less than the resulting apparent volume of the mass. This may be due to air mechanically inclosed, to flaws in molding, and volume changes due to the action of dissolved salts upon the clay gel.

In a series of experiments the volume changes taking place on working up a number of dry clays have been measured very carefully, the results of which are compiled in Table II.

\section{TABLE II}

Volume Changes in Working Dry Clays

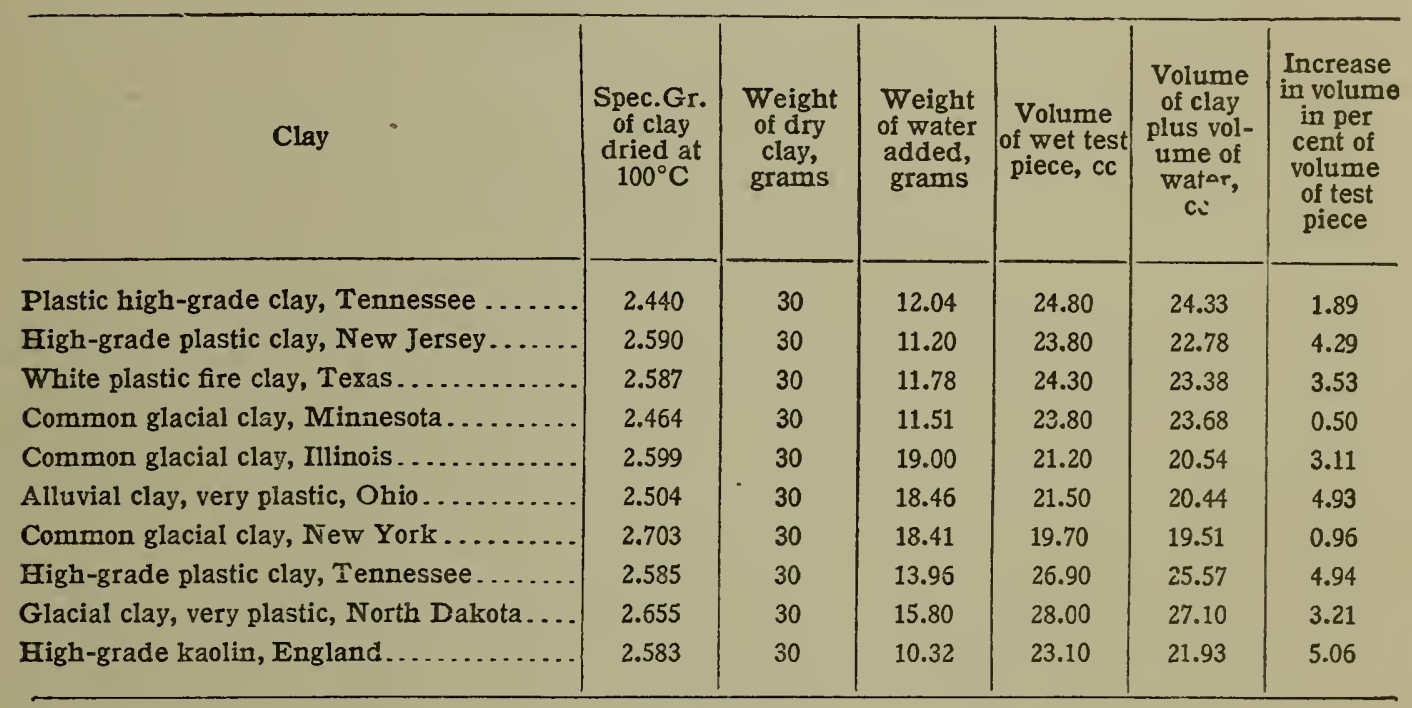

A short experimental series was also undertaken for the purpose of showing the rate at which several clays lose their residual water when subjected to conditions of decreasing vapor tensions. Five clays were made up into thoroughly homogeneous plastic pastes and placed into tared capsules provided with tight fitting lids and weighed.

The clays thus treated in the order of their apparent plasticity and difficulty of drying are as follows:

No. I. An impure, exceedingly plastic glacial clay from Fort Pierre, N. Dak.

No. 3. A ball clay from Whitlock, Tenn., through the Potter's Supply Company. 
No. 6. A very plastic kind of fire clay from Edwards County, Tex.

No. 7. A plastic glacial clay from Albert Lea, Minn.

No. ro. A high grade English china clay, Pool No. I.

Of each clay five such samples were prepared. Five concentrations of sulphuric acid were then made up, of which a sufficient quantity was poured into each of five desiccators. These solutions of sulphuric acid represented final vapor tensions of from I 2 to $0.15 \mathrm{~mm}$, at $25^{\circ} \mathrm{C}$, taking the water given off by the clays into account. After weighing the closed capsules containing the clay samples, which averaged about five grams, the covers were removed and one pat of each clay placed in every desiccator. They were allowed to remain in these for $2 \mathrm{I}$ days when they were again weighed. The room temperature fluctuated between $2 \mathrm{I}^{\circ}$ and $26^{\circ} \mathrm{C}$. It was thus possible to compare the water losses suffered by each clay for the difference in vapor tension given above by subtracting from the percentage of water at $12 \mathrm{~mm}$ the percentage contents at the lower tensions. In this way the curves of Fig. 2 were obtained. In these only the residual water is considered, beginning with the amount of water left under a vapor tension of $12 \mathrm{~mm}$ to which all clays were subjected. It is at once observed that the amount of the residual water varies, being largest, 5.3 per cent, in the case of No. I and lowest, o.85 per cent, for No. Io. The more plastic and "sticky" clays, therefore, show the highest water loss for the given difference in vapor tension. It is evident from this that the rate of drying at a constant temperature likewise varies for the different clays being slowest in the most plastic materials. These facts indicate not only varying amounts of plastic clay base in the different clays, but deepseated variations in the micellean structure itself as well, since it is hardly probable that the larger content of residual water remaining in an impure material such as No. 1 could be attributed to a higher content of theoretical clay substance $\left(\mathrm{Al}_{2} \mathrm{O}_{3} 2 \mathrm{SiO}_{2} \cdot 2 \mathrm{H}_{2} \mathrm{O}\right)$ than is contained in the far purer clays Nos. 3,6 , and ro.

After having been replaced in the desiccators the samples were again weighed after three months and were found to possess practically the same weight. It seems thus that the conditions of equilibrium had been approached sufficiently close for the purpose of the experiment. 


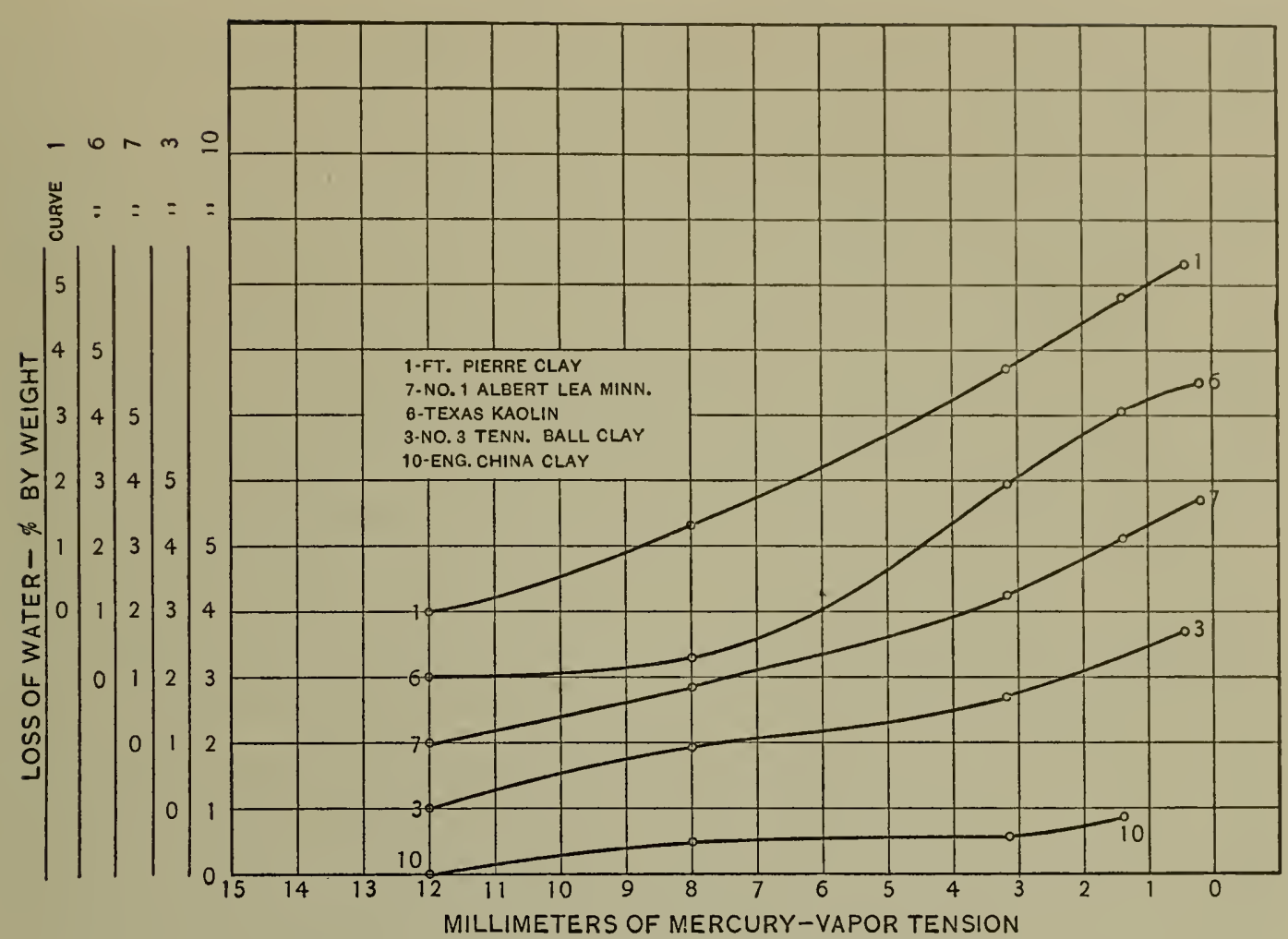

Fig. 2.-Relation between loss of water and vapor tension of fire clays.

The drying shrinkage of a homogeneous clay body of geometrical symmetry, free to contract, is uniform in all directions. The most accurate valuation of shrinkage is obtained by means of volume measurements, though for practical work the linear dimensions in the wet and the dry state will suffice. The linear shrinkage is readily deduced from the volumetric values by the relation:

$$
\% l=\frac{\sqrt[3]{v_{1}}-\sqrt[3]{v_{2}}}{\sqrt[3]{v_{1}}} \text { IOO }
$$

where $v_{1}$ and $v_{2}$ are the volumes in the wet and the dry state, respectively, and $l$ is the linear shrinkage in terms of the wet length. If the linear contraction is desired in terms of the dry length, the denominator of course becomes $\sqrt[3]{v_{2}}$. The assumption commonly made that the volume shrinkage is equal to three times the linear shrinkage is not sufficiently exact even for practical purposes. If the initial (wet) volume is assumed to be unity and $a=$ linear shrinkage, the dry volume becomes $(\mathrm{I}-a)^{3}$, 
or $\mathrm{I}-3 a+3 a^{2}-a^{3}$. The shrinkage, therefore, $=3 a-3 a^{2}+a^{3}$, in which the term $a^{3}$ may be neglected, but not $3 a^{2}$.

Owing to the fact that the amount of water used in making up the same clay is not constant, the apparent volume of a lump of a definite weight of dry clay varies somewhat even with the most painstaking manipulation. Likewise the pore space remaining in the dried material does not remain the same in each case. For this reason it has been thought advisable to express the volume shrinkage in terms of the true clay volume; i. e., weight of dry clay divided by its density in the powdered state.

In the study of the drying behavior of clays two factors are of considerable significance, viz, the amount of water required to produce a plastic mass and the shrinkage on drying. Ordinarily the more plastic and difficultly drying clays require the highest amounts of water and show the greatest drying shrinkage, although there are exceptions to the rule. Some materials, owing to peculiar conditions, such as excessive fineness of the granular matter, may dry more difficultly with lower water of plasticity and shrinkage than clays with higher water content and shrinkage.

In seeking for approximate values expressing the drying behavior of a clay by means of an experimental test it is necessary to know the total amount of water required to develop plasticity, the volume shrinkage, and the time required to evaporate the shrinkage water at a constant temperature. This means that the length of the test specimen must be carefully measured at short intervals. Then, knowing the time required to reach the point at which shrinkage ceases, and the total shrinkage, an estimate may be made of the drying behavior of the clay by multiplying together the values obtained for time and shrinkage. This numerical expression is inversely proportional to the ease with which it dries.

For the purpose of illustration the following description of a similar experiment might be cited. ${ }^{8}$ Spheres of clay $7.1 \mathrm{I} \mathrm{cm}$ in diameter were made, maintained for some time under conditions of moisture saturation in order to establish a condition of equilibrium, and then placed in an oven at a constant temperature of $60^{\circ} \mathrm{C}$, regulated by means of a thermostat. The diameter of

${ }^{8}$ E. F. Lines, Trans. Am. Ceram. Soc. $I I, \mathrm{I} 46$. 
the sphere was measured from time to time by means of a vernier caliper. Thus the point was determined at which shrinkage ceased. A shale was found to possess a linear shrinkage of 4.0 per cent in terms of the diameter in the dry state, and it lost its shrinkage water in 4 hours. The factor in this case would be $4 \times 4=$ I6. Similarly, a washed No. 2 fire clay showed a shrinkage of 6.5 per cent and lost its shrinkage water in 5.I hours, giving a value of $6.5 \times 5.1=33.15$. Finally, a fine-grained, glacial clay, very difficult to dry, possessed a shrinkage of 8.5 per cent and ceased contracting in 8.9 hours, resulting in $8.5 \times$ $8.9=75.65$.

Since these measurements were made under strictly comparable conditions as to drying temperature, initial size, and shape (spherical) of the test pieces, the numerical values are inversely proportional to the ease with which the clays dry in practice. The actual drying behavior of these clays was well expressed by the factors, the shale being the easiest and the glacial the most difficult to dry under commercial conditions.

Practically the same results could be obtained by determining the initial diameter and weight of the test piece, weighing it at frequent intervals, and measuring the size in the dried condition. The time when the calculated weight of shrinkage water (which should be equal in volume to the volume shrinkage) has been evaporated could be readily obtained from the time-weight curve.

The rate of drying has some influence upon the shrinkage of clays, inasmuch as rapid heating is said to result in a lower total contraction. As far as known to the writer, no experimental proof of this statement is at hand.

\section{DIFFICULTLY DRYING CLAYS}

Clays are subject to two kinds of difficulties in drying which are opposite in character. They may give trouble, due either to an excess of plastic material or to a deficiency of it. In the first case the system of capillaries is so extremely fine that the flow of water through it is very slow and becomes the more restricted as shrinkage progresses. Owing to the fact that such clays show a very large contraction in volume, the capillary channels necessarily become smaller and.smaller on drying, thus causing the difficulty of expelling the water to increase. 
(a) Causes of Cracking.-The result is inevitably that the rate of surface evaporation is greater than the flow of water toward the surface, a condition which gives rise to strains and more or less marked ruptures.

In the second case the amount of clay bonding matter is so low that the body does not possess the tensile strength needed to withstand the strain caused by the closing up of the particles near the evaporating surface. The result of this condition is that the clay gives way and cracks.

In order to overcome these two classes of difficulties, some remedial measures are available. These are for the excessively plastic clays dilution by means of nonplastic materials like sand or ground, calcined clay (grog), or drying of the ware under carefully regulated conditions with special reference to the maintenance of a high humidity in the drying until the clay has become uniformly heated throughout, or by using the preliminary heating treatment which is the subject of this work.

As regards weak clays, lacking in plastic clay matter, the means open for overcoming the difficulty consist in developing the available plasticity to its maximum by means of storing in the wet condition, by grinding and thorough pugging, by the use of slightly acid tempering water (in some cases), and finally by the incorporation of a more plastic material, which offers the most positive solution of the case.

(b) Effect of Nonplastic Materials.-The addition of granular, nonplastic material to an excessively plastic clay is made for the purpose of improving the working quality by reducing its "stickiness," decreasing the drying shrinkage, and with it the tendency to warp and crack in drying, and of lowering the kiln loss due to strains caused in drying and the impermeability of the dense clay to air needed for the oxidation of the organic matter present in all argillaceous materials. Nonplastic matter, intimately blended with the clay, thus exerts a decided influence upon the working qualities of the latter, affecting the penetration of water into the pore system, the shrinkage in drying and burning, as well as the porosity in the dried and burnt condition. Its effects, hence, are far reaching, since they are intimately connected with the final use of the product, its resistance to weathering agencies, abrasion, etc. 
When any granular, nonplastic material of uniform size is incorporated in a strongly plastic clay several effects may be observed. The volume shrinkage, providing the same percentage by volume of water is maintained, may be found to increase up to a certain content of the nonplastic constituent, but beyond this point it will decrease. The density of the clay mass may thus be said to increase to a maximum. After passing it the shrinkage decreases while the porosity rises. This effect is brought out more or less clearly according to the granulometric composition of the nonplastic material added and the initial content of such material in the clay.

It is evident that on introducing small amounts of a nonplastic material into a plastic clay the spongelike matrix envelops the hard grains and the total pore space per unit volume, assuming that the sand, or whatever material may be added is free from pores, has been decreased. If the total water content be kept constant, some of the pore water therefore becomes shrinkage water, with the result that the contraction in drying is increased. From this it follows that since the pore water, and hence the pore space, has been decreased in volume the density of the mass must have increased. Upon continuing the addition of nonplastic material the point is reached when contact is established between the incorporated grains, and therefore some of the shrinkage water again becomes pore water. Shrinkage therefore decreases from this point on and the porosity increases.

If in the case of a difficultly drying, exceedingly plastic clay it is decided to add sand for the purpose of making it easier to dry, this addition should be carried beyond the point of maximum density, so that a larger pore space, and hence an increased evaporation and outlet area is produced.

In tracing the effect of nonplastic matter the assumption has been made above that the water content be kept constant. If this condition is not fulfilled but the attempt is made to maintain constant consistency, the above facts still hold, although the effects are not so marked. In determining the drying shrinkage of five low grade, plastic clays with varying percentages of a very uniform sand (20-3O mesh), and at the same time aiming to keep the consistency constant, it was possible in each case to fix clearly the point of maximum density. 
The size of grain of the nonplastic material is necessarily an important factor in the resulting density and the system of pore spaces. Fine-grained sand, for instance, at the point of maximum density will result in a more porous structure than coarser grained at the same point. With equal water content a fine nonplastic will bring about a stiffer consistency than coarser-grained material. As regards a mixture of grains of various sizes, the same statements hold that have been made with reference to the natural granular constituents of clays.

\section{PREHEATING}

(a) The Clays Used in the Experiments.-Since this bulletin deals solely with the study of the preheating treatment of clays and its effect upon clays, a detailed consideration of other methods bringing about similar results can not be undertaken at this time.

For the purpose of the investigation 14 clays were selected, covering a wide range of chemical and mineralogical compositions. Their character is indicated by the following descriptive remarks:

No. $I$.-An exceedingly plastic clay, very similar in behavior to bentonite, from Fort Pierre, N. Dak. It is impossible to dry this material without cracking. Its fineness of grain, is remarkable. Apparently it contains some calcium carbonate in a state of extremely fine subdivision.

No. 2.-St. Louis fire clay, Highland Fire Clay Co., St. Louis, Mo. A high-grade fire clay, but lacking in plasticity, owing to insufficient reduction of clay grains. Grinding at once improves the plastic quality simply by disintegrating the coarser, wax-like clay particles.

No. 3.-Tennessee ball clay No. 3 (Potter's Supply Co.), from Whitlock, Tenn. A clay of great plasticity and bonding power. It dries without difficulty excepting when fabricated into large pieces, when care must be taken to prevent cracking by maintaining a high humidity during the initial stages and by keeping the drying temperature down as low as possiple.

No. 4.- Prall sagger clay, Woodbridge, N. J., a decidedly plastic material of excellent bonding power and of safe drying behavior. It contains coarser grains of quartz. 
No.5.-Pike's No. 20 ball clay, a high-grade English plastic material which when used alone has a decided tendency to warp and which when made up into large pieces must be dried with great care to prevent cracking. Its bonding power, which makes it valuable, is very high and by some it is considered the strongest material of this kind on the market.

No. 6.-Texas kaolin, "Lone Star" brand, from Edwards County, Tex. A fire clay consisting of clay grains and extremely fine clay matter. Grinding increases the plasticity of this clay immensely and in this way it is capable of great improvement by the reduction of the comparatively coarse clay grains. It does not seem to give trouble in drying.

No. 7.-An extremely fine-grained glacial clay from Albert Lea, Minn., of considerable plasticity, but troublesome to dry.

No. 8.- Joint clay, from Urbana, I1l. A plastic glacial clay, difficult to dry, due not so much to great fineness of grain as to "joint" structure which is indicated by the fact that bricks made from it on drying split vertically into more or less irregular cubes.

No. 9.-Albany slip clay, a fine-grained glacial clay from northern New York, low in bonding power, but showing sufficient plasticity.

No. Io.-English China clay, J. Poole No. I, considered a high grade of kaolin, not commonly imported, of excellent plasticity and yet producing a fine white color.

No. II.--Joint clay, Peoria, Ill., a typical fine-grained glacial clay, giving some trouble in drying.

No. I2.-A typical alluvial clay from Groveport, Ohio, of decided plasticity, somewhat troublesome to work and dry. Probably quite high in ferric oxide, since on burning a fine red color is developed.

No. 13.-A No. 2 fire clay, highly impregnated with ferric oxide, from Athens, Ohio, very plastic, with some tendency to crack in drying though excellently suited for admixture with shale owing to its ease of slaking down on contact with water.

No. I4.-A glacial, calcareous clay from Heron Lake, Minn., possessing good plasticity and working properties though somewhat too fine grained for drying when made into larger pieces. 
In the effort to correlate the drying shrinkage with the fineness of grain and the general plastic behavior of these different clays the following determinations were made:

I. Drying shrinkage in the normal condition.

2. Fineness of grain by means of the mechanical analysis.

3. Resistance offered by mixtures of clay and water to the passage of a paddle in the Stormer viscosimeter.

(b) Drying Shrinkage.-In determining the drying shrinkage of the clays they were made up with water to "plastic" consistency, which, in spite of its apparent indefiniteness, is a condition fairly sharply defined in the hands of an experienced operator. Owing to the fact that there exist no other means of maintaining a constant consistency, it was necessary to depend solely upon the judgment of the manipulator. In some preliminary experiments, however, it was shown that the water content representing good working quality could be checked for the same clay with satisfactory accuracy since at approximately the proper working consistency the clays are quite sensitive to a deficiency or excess of water. This property varies somewhat with different materials, very plastic clays being less sensitive to variations in water content than those higher in nonplastic matter. After having been allowed to stand over water for 24 hours the clays were molded by hand into approximately cylindrical test pieces which were at once weighed and their volume determined. The weighing was done in closed tin cylinders to prevent loss by evaporation. The volume of each cylinder was determined by immersion in petroleum making use of a narrow-necked flask and obtaining the volume of liquid displaced by means of a burette calibrated to $0.1 \mathrm{cc}$ which permitted of easily reading to $0.05 \mathrm{cc}$. The weight of the clay cylinders varied between 20 and 35 grams and the volumes from I 2 to $22 \mathrm{cc}$. After the determination of weight and volume the test pieces were dried at $60^{\circ}$ till the weight was constant and finally at $100^{\circ}$. The dry specimens were then weighed and immersed in melted paraffine at a sufficiently high temperature so that the liquid penetrated into the interior, but dripped off completely on removing the piece from the bath. When cool the cylinders were placed in petroleum for several hours and the volume determined as before. 
In Table III the volume shrinkage of the clays in terms of the dry volume of the cylinder and of the true volume of the clay as well as the linear shrinkage in terms of the wet length are compiled. For purposes of comparison the shrinkage referred to the true clay volume is to be preferred owing to the variable factor of the pore space which depends upon the character of the clay, the method of manipulation, etc.

The shrinkage expressed in terms of the real clay volume is readily calculated from the relation:

$$
s=\frac{d\left(v_{1}-v_{2}\right)}{w} \text { where- }
$$

$s=$ volume shrinkage in terms of the true clay volume.

$d=$ specific gravity of powdered dry clay.

$v_{1}=$ volume of clay cylinder in the wet state.

$v_{2}=$ volume of clay cylinder in the dried state.

$w=$ weight of the dried cylinder in grams.

TABLE III

Shrinkage of Various Clays

\begin{tabular}{c|c|c|c|c}
\hline No. of clay & $\begin{array}{c}\text { Specific gravity } \\
\text { of powdered } \\
\text { dry clay }\end{array}$ & $\begin{array}{c}\text { Volume shrinkage } \\
\text { in per cent of } \\
\text { volume of } \\
\text { dry test piece }\end{array}$ & $\begin{array}{c}\text { Volume shrinkage } \\
\text { in per cent of } \\
\text { true clay volume }\end{array}$ & $\begin{array}{c}\text { Linear shrinkage } \\
\text { in per cent of } \\
\text { the wet length }\end{array}$ \\
\cline { 1 - 3 } 1 & 2.451 & 68.57 & 99.80 & 15.97 \\
2 & 2.551 & 23.40 & 30.30 & 6.77 \\
3 & 2.770 & 38.10 & 60.73 & 10.20 \\
4 & 2.596 & 34.50 & 54.80 & 9.41 \\
5 & 2.577 & 48.19 & 61.96 & 12.28 \\
6 & 2.510 & 36.80 & 60.10 & 9.92 \\
7 & 2.580 & 36.20 & 49.00 & 9.79 \\
8 & 2.603 & 30.30 & 41.85 & 8.44 \\
9 & 2.784 & 16.90 & 25.80 & 5.07 \\
10 & 2.476 & 21.05 & 34.80 & 6.17 \\
11 & 2.575 & 32.20 & 49.00 & 8.89 \\
12 & 2.680 & 37.86 & 51.09 & 10.15 \\
13 & 2.768 & 38.00 & 49.05 & 10.18 \\
14 & 2.645 & 27.30 & 42.65 & 7.72 \\
\hline
\end{tabular}


The specific gravity of the clays was determined by means of the pycnometer with the usual precautions as regards exhaustion of the air and correcting for temperature.

The linear shrinkage was calculated from the condensation in volume.

The clays examined, with the exception of three, the Highland fire clay, the Albany slip clay, and the English china clay, belong to the more difficultly drying materials when made up into heavier products. The clay from Fort Pierre, N. Dak., is in a class of its own, and it appears to be impossible to dry it under any conditions.

(c) Mechanical Analysis. - The mechanical analysis as practiced by agricultural and ceramic investigators consists in the separation of grains of certain arbitrary size limits by means of sieves and further separation by means of sedimentation, elutriation or centrifugal action, water being used as the medium of flotation. For the purpose of the ceramist the Schulze apparatus, in which the separation of the grain is effected by the method of elutriation, is commonly used and meets the technical requirements owing to the simplicity and convenience of its arrangement. It consists of three tin-lined copper cans with conical bottoms, 2 , 5, and $6 \frac{15}{16}$ inches in diameter, respectively, through which water is allowed to flow at a constant rate, I $76 \mathrm{cc}$ per minute. It is readily seen that this results in the greatest velocity in the narrowest and the lowest in the widest can. With the diameters of the cans and the volume of water given, the largest particles settle in can No. I, averaging about $0.0577 \mathrm{~mm}$ diameter, the next smaller in No. 2, averaging about $0.0354 \mathrm{~mm}$, while in No. 3, the average size approximates $0.0167 \mathrm{~mm}$. Particles still finer, about $\pm 0.005 \mathrm{~mm}$, are carried off by the overflow.

The average size represents the microscopic measurement of $5^{\circ}$ particles of eách sediment and is the arithmetical mean. In this connection the difficulty of obtaining the true mean diameter is fully realized, but for the work in question this method has been preferred to the method of mean integrals, since it was not desired to calculate a surface factor. After the water escaping from the third can appears to be clear the cans are emptied by siphoning down to the conical bottom. The water and clay in this part of the cans is washed out, evaporated to dryness, and weighed. The amount 
of the finest particles is obtained by difference. Before being placed in the elutriating apparatus the sample of the dry clay, the amount of which is usually 50 grams, is made up with water to form a thin slip, deflocculated by the addition of caustic soda or sodium oxalate according to the nature of the clay and mechanically shaken for one hour. The clay suspension is then passed through a series of small conical sieves, telescoped together, ranging from 20 to $\mathrm{I} 2 \mathrm{O}$ mesh. After washing and drying the residues on each sieve are weighed. The material which passes the I $20-m e s h$ sieve is collected and introduced into the elutriating apparatus.

The water flowing through the cans is taken from the tap, but is filtered through beds of sand and charcoal. Its temperature is kept constant by heating to a certain temperature and regulation by means of a thermostat. The separation of the sediments is considered successful when the residues dry down without cracking. If the latter occurs, some of the clay matter has been retained, and the test is repeated, the clay sample being deflocculated more thoroughly or another reagent is employed such as sodium oxalate. In extreme cases the deflocculating solution is dropped slowly into the first can for a number of hours. Certain precautions must be observed in the operation of the elutriating apparatus, such as to start with a reduced flow of water until the first can appears to be comparatively clear when the current is brought to the standard velocity. The time required for the elutriation varies from ro to 24 hours, according to the nature of the clay. When adjusted the device needs practically no attention.

The results of the mechanical analyses of the clays examined are compiled in Table IV.

From the results of the mechanical analysis a numerical value expressing the fineness of grain of the clay as a whole might be calculated. Since the weights of the fractions are known, the average diameters (by microscopic determination) and the specific gravity of the powder may easily be obtained a factor expressing the relative total surface area may be computed, which J. W. Mellor ${ }^{8}$

9 J. W. Mellor, Jackson's and Purdy's Surface Factors. Trans. English Ceram. Soc. 9 , p. 94-rI4. 


\section{TABLE IV}

\begin{tabular}{|c|c|c|c|c|c|c|c|c|c|c|c|c|}
\hline \multirow{2}{*}{$\begin{array}{l}\text { No. } \\
\text { of } \\
\text { clay }\end{array}$} & \multicolumn{7}{|c|}{$\begin{array}{l}\text { Residue left on sieves in per cent by weight } \\
\text { of dry clay }\end{array}$} & \multicolumn{3}{|c|}{$\begin{array}{l}\text { Sediments left in } \\
\text { can, in per cent by } \\
\text { weight of dry clay }\end{array}$} & \multirow{2}{*}{ 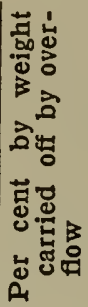 } & \multirow{2}{*}{$\begin{array}{l}\text { Kind and amount } \\
\text { of reagent em- } \\
\text { ployed per } 50 \text { grams } \\
\text { of clay }\end{array}$} \\
\hline & $\left|\begin{array}{c}20 \\
\text { mesh }\end{array}\right|$ & $\begin{array}{c}40 \\
\text { mesh }\end{array}$ & $\begin{array}{c}60 \\
\text { mesh }\end{array}$ & $\begin{array}{c}80 \\
\text { mesh }\end{array}$ & $\begin{array}{c}100 \\
\text { mesh }\end{array}$ & $\begin{array}{c}120 \\
\text { mesh }\end{array}$ & $\begin{array}{l}\text { resi- } \\
\text { dues } \\
\text { on } \\
\text { sieves }\end{array}$ & $\begin{array}{c}\text { Can } \\
\text { No. } 1\end{array}$ & $\begin{array}{l}\text { Can } \\
\text { No. } 2\end{array}$ & $\begin{array}{l}\text { Can } \\
\text { No. } 3\end{array}$ & & \\
\hline 1 & & & & & & & 2.32 & 0.35 & 0.39 & 1.12 & 95.52 & 1 c c $\frac{\mathrm{N}}{10} \mathrm{NaOH}$ \\
\hline $\begin{array}{l}2 \\
3\end{array}$ & Trace & 11.75 & 7.03 & 4.10 & 5.30 & 0.77 & $\begin{array}{r}28.98 \\
\text { Trace }\end{array}$ & $\begin{array}{r}14.74 \\
0.02\end{array}$ & $\begin{array}{r}11.79 \\
0.24\end{array}$ & $\begin{array}{l}3.95 \\
0.43\end{array}$ & $\begin{array}{l}40.57 \\
99.31\end{array}$ & $\begin{array}{l}200 \mathrm{cc} \frac{\mathrm{N}}{10} \mathrm{Na}_{2} \mathrm{C}_{2} \mathrm{O}_{4} \\
80 \mathrm{cc} \frac{\mathrm{N}}{10} \mathrm{NaOH}\end{array}$ \\
\hline $\begin{array}{l}4 \\
5\end{array}$ & & & & & & & 1.17 & 2.83 & 8.28 & 2.01 & \begin{tabular}{|l|}
85.71 \\
99.00
\end{tabular} & $500 \mathrm{c} \mathrm{c} \frac{\mathrm{N}}{10} \mathrm{NaOH}$ \\
\hline 6 & 0.05 & 0.18 & 2.93 & 2.60 & 5.35 & 0.85 & 11.96 & 13.65 & 19.07 & 5.14 & 50.18 & 50 c c $\frac{\mathrm{N}}{10} \mathrm{NaOH}$ \\
\hline 7 & 0.04 & 0.06 & 0.04 & 0.04 & 0.04 & 0.02 & 0.24 & 0.21 & 1.04 & 0.96 & 97.31 & $75 \mathrm{cc} \frac{\mathrm{N}}{10} \mathrm{NaOH}$ \\
\hline 8 & 0.61 & 1.49 & $\underbrace{1.74}$ & 0.63 & 0.55 & 0.11 & 5.13 & 3.15 & 34.50 & 9.72 & 47.50 & $100 \mathrm{c} \mathrm{c} \frac{\mathrm{N}}{10} \mathrm{NaOH}$ \\
\hline 9 & 0.02 & 0.02 & & 0.0 & & & 0.08 & 0.24 & 6.34 & 8.74 & 84.60 & 30 c c $\frac{10}{10} \mathrm{NaOH}$ \\
\hline 10 & & & & & & 0.02 & 0.02 & 0.02 & 10.90 & 9.52 & 79.54 & $30 \mathrm{cc} \frac{\mathrm{N}}{10} \mathrm{NaOH}$ \\
\hline 11 & 0.33 & 0.66 & 0.35 & 0.16 & 0.27 & 0.04 & 1.81 & 2.28 & 34.09 & 10.69 & 51.13 & 100 c c $\frac{N}{10} \mathrm{NaOH}$ \\
\hline 12 & $\mid 0.64$ & 0.98 & 1.24 & 1.10 & 3.54 & 0.24 & 7.74 & 14.30 & 23.08 & 7.06 & 47.82 & $180 \mathrm{cc} \frac{\mathrm{N}}{10} \mathrm{Na}_{2} \mathrm{C}_{2} \mathrm{O}_{4}$ \\
\hline 13 & 1.54 & 1.83 & 2.86 & 0.96 & 2.22 & 0.18 & 9.59 & 5.66 & 8.54 & 8.24 & 67.97 & \\
\hline 14 & 0.14 & 0.28 & 0.46 & 0.34 & 0.46 & 0.04 & 1.72 & 0.98 & 8.03 & 9.03 & 80.24 & 75 c c $\frac{N}{10} \mathrm{NaOH}$ \\
\hline
\end{tabular}

expresses by the formula:

$$
\frac{6}{s}\left(\frac{W_{1}}{d_{1}}+\frac{W_{2}}{d_{2}}+\frac{W_{3}}{d_{3}}+\ldots\right)
$$

Here $s=$ mean specific gravity of the powder, $W_{1}, W_{2}, W_{3} \ldots$ the weights of the fractions, and $d_{1}, d_{2}, d_{3}$ the average diameters of the grains in the several fractions.

The greater the surface factor the finer is the material, and hence this value may be used to give a relative approximation which serves sufficiently well for purposes of comparison.

Where the limiting diameters of the fractions are known-i. e., the sizes of the largest and the smallest particles for every separation-the mean integral diameter may be calculated from the formula ${ }^{10}$

$$
\sqrt[3]{\frac{\left(d_{1}+d_{2}\right) \cdot\left(d^{2}{ }_{1}+d^{2}\right)}{4}}
$$


in which the limiting diameters are represented by $d_{1}$ and $d_{2}$. The value of this average diameter may then be substituted in the formula for the surface factor given above.

In all of this work the assumption has been made, necessarily, that all the particles are spherical in shape, which of course is not true. Again, the surface factor thus calculated can make no claim to scientific accuracy, owing to the fact that it is difficult to obtain the average sizes of the grains represented by the various sediments, and practically impossible to determine the mean dimension of the particles carried off by the overflow with any degree of correctness. Owing to the fineness of the material floated off its surface valuation constitutes the greater part of the total surface factor. Furthermore, many of the apparent grains are aggregates of still finer material, and it is almost absurd to speak of an average size for the clayey matter. The material carried off contains practically all of the plastic clay substance and in addition the finest particles of granular matter.

In comparing the clays as to their drying behavior the amount of overflow material expressed in per cent is used as the basis of comparison. Generally speaking, therefore, the statement might be made that clays should dry the more difficultly the finer grained they are, the more matter is washed out of them at the low velocity maintained in the third can of the Schulze elutriating apparatus, assuming that the clay substance is of the same character in all of them. Since the latter assumption, however, is inadmissible, the above generalization holds only in a limited sense, in comparing clays of one kind. Still further modifications are made necessary by the size factor of the granular matter, as has already been pointed out elsewhere.

Similarly, a statement to the effect that clays showing the greatest shrinkage are most difficult to dry can not be accepted without qualification for the same reasons applying to the question of fineness. Granted that the greatest volume shrinkage results in the greatest strain upon the clay structure, the fact remains that clays differ widely in tensile strength and hence in the ability to meet these stresses.

If in spite of these objections an attempt is made to differentiate between the clays as to their relative difficulty of drying, it 
is evident that such a classification may serve only as a general guide. This approximation was obtained by multiplying the drying shrinkage expressed in terms of the true clay volume by the fraction carried off in the overflow of the Schulze apparatus. From this definition it appears that the higher the numerical value thus obtained the more difficultly should the clay dry other things being equal. The drying factors thus calculated are collected in Table V.

\section{TABLE V}

Drying Factors

\begin{tabular}{|c|c|c|c|c|c|c|c|}
\hline Clay No. & 1 & 2 & 3 & 4 & 5 & 6 & 7 \\
\hline $\begin{array}{l}\text { A. Fraction carried off by over- } \\
\text { flow }\end{array}$ & 0.955 & 0.406 & 0.993 & 0.857 & 0.990 & 0.502 & 0.973 \\
\hline $\begin{array}{l}\text { B. Drying shrinkage in per } \\
\text { cent of true clay volume...... }\end{array}$ & 99.80 & 30.30 & & 54.80 & 61.96 & 60.10 & 49.00 \\
\hline Factor $\mathbf{A} \times \mathbf{B}$ & 95.31 & 12.30 & 60.30 & 46.96 & 61.38 & 30.17 & 47.67 \\
\hline Clay No. & 8 & 9 & 10 & 11 & 12 & 13 & 14 \\
\hline $\begin{array}{l}\text { A. Fraction carried off by over- } \\
\text { flow....................... }\end{array}$ & 0.475 & 0.846 & 0.795 & 0.511 & 0.478 & 0.680 & 0.802 \\
\hline $\begin{array}{l}\text { B. Drying shrinkage in per } \\
\text { cent of true clay volume....... }\end{array}$ & 41.85 & 25.80 & 34.80 & 49.00 & 51.09 & 49.05 & 42.65 \\
\hline Factor $\mathrm{A} \times \mathrm{B}$. & 19.90 & 20.83 & 27.67 & 25.04 & 24.43 & 33.35 & 34.17 \\
\hline
\end{tabular}

(d) Viscous Condition of Clay Suspensions in Water.-In previous work ${ }^{11}$ the writer has made the attempt to correlate the plastic behavior of different fine-grained clays by determining the tenacity of clay slips, representing various mixtures of clay and water, using a modified Coulomb viscosimeter. He was successful in differentiating several well-known clays in a way which agreed with practical observation. In carrying on these experiments it was fully realized, however, that the comparative results obtained do not express viscosity in its proper physical meaning, but that they represent complex functions, the resultant of which seems to be related to the plastic condition of the material. From practical experience it is known that the more plastic 
a clay is the more power is required to force it through an auger machine or pug mill. Owing to the fact that we are dealing in this case with suspensions, it is evident that various factors enter into the question such as the viscosity of the water which has dissolved some of the salts contained in the clay, the mechanical resistance of the suspended granular matter, as well as that offered by the flocculent matter to the passage through water, etc. In addition the practical difficulty due to the tendency of the materials to settle must be considered. Owing to the fact that the latter feature is especially annoying, it was decided to make use of an apparatus employing a paddle in place of the disc. Such an instrument was found already on the market in the Stormer viscosimeter, which consists in brief of a vertical shaft to which a paddle is attached and which is driven by means of a simple gearing from a grooved pulley. Motion is imparted to the latter by means of a weight attached to the pulley by a cord. The weight used in these experiments was 200 grams. A revolution counter is connected to the vertical shaft. The method of operating the instrument is very simple. The liquid is poured into a square receptacle, taking care that the same level is maintained for each test. The cup is then raised so that the paddle is immersed and by releasing a brake the weight is caused to descend, thus revolving the pulley and transmitting motion to the paddle shaft. By means of a stop watch indicating one-fifth seconds the time required by the paddle to make Ioo revolutions is determined. It is also necessary to obtain the time taken for the same number of revolutions in air, and to deduct this reading from every determination. The resistance offered by water is taken as unity by dividing the time required to make Ioo revolutions with the paddle immersed in water into the time required to make the same number of turns in the clay suspension, deducting the air constant from each reading.

A brief consideration of the principle of the apparatus will show that owing to the variable speed in the different media the results are not strictly comparable. This together with the variable friction constant of the mechanism itself causes the variations in the experimental results to be quite large. How- 
ever, for the purpose in view the object of carrying on this work was merely to obtain a rough classification of the clays as to their plastic character under the assumption that the resistance offered by clay suspensions of equal content in solids is a function of their plastic behavior, an assumption, however, for which a general proof has not yet been established. In this connection it was desired to locate by comparison certain of the clays examined which have been found to be especially troublesome in drying.

The preparation of the clays for the test consisted in weighing out a certain quantity of the dried material and of a sufficient amount of water and shaking them by mechanical means, so that the slip became as thick as possible and yet permitted the paddle to revolve. This heavy suspension was diluted gradually, so that the desired concentrations of clay were obtained. In this manner a number of dilutions were made and their relative resistances determined.

The initial clay suspensions were shaken in wide-mouth bottles containing a little shot to facilitate the breaking up of the clay particles. The slip was then shaken through a 2o-mesh sieve and poured into the viscosimeter cup.

The results of this work are shown in the diagram of figure 3 . In spite of the irregularity of the curves it is at once observed that the clays arrange themselves into three groups. That showing the most rapid increase in resistance or tenacity comprises the plastic clays of the purer type, including, however, one member of the impure clays, the material from Fort Pierre. The latter is of such a highly plastic nature that its presence in this group is not surprising. The second group contains all of the glacial clays which show remarkable similarity in this respect. In the third group the Highland fire clay appears, which, as the sole representative of its class, takes its proper place.

The higher degree of plasticity on the part of the purer clays is made very prominent, and this is due not only to the greater fineness of grain, since two of the glacial clays approach them in this respect, but primarily to the lack of granular matter which, though very fine, is ever present in the impure surface clays. 


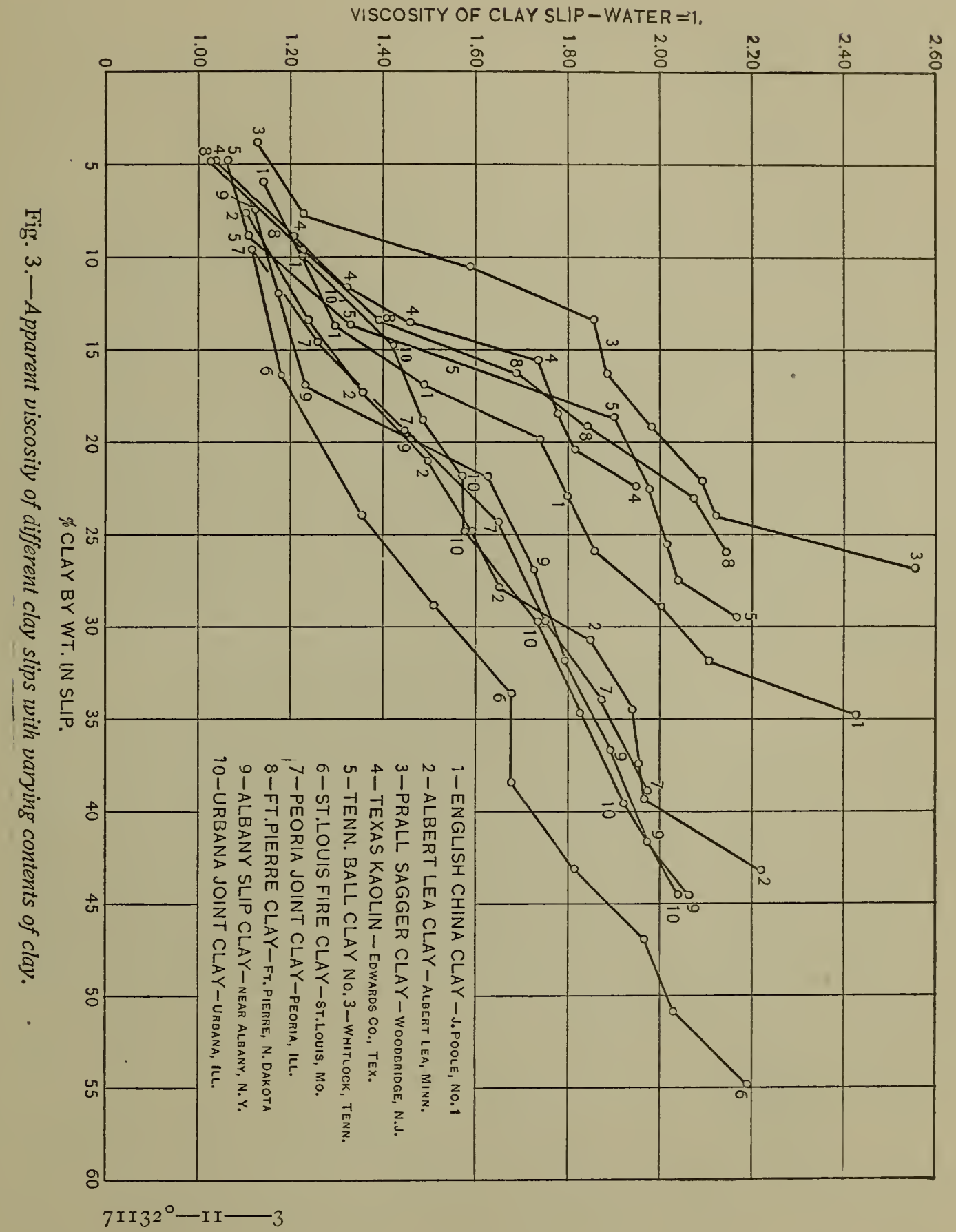


The latter may reach the highly plastic development of the purer clays, as is shown by the Fort Pierre material, but this is a rare exception. The extreme at the plastic side of the first group is represented by the Prall sagger clay, at the lower end by the English China clay. In this connection the fact must be remembered that all of the clays represent the maximum plastic development, owing to their long-continued stirring in contact with a comparatively large amount of water.

Although this alignment of the clays enables us to obtain an insight into their plastic behavior, we can not draw any deductions as to their difficulty of drying, which, as has been said before, is not necessarily coincident with the highest plasticity. Thus, No. 4 , the New Jersey clay, though it is very plastic and possesses high bonding power, offers no decided difficulties in drying, while the joint clays, which are considerably less plastic, become very troublesome in this respect. In considering the subsequent work we must keep clearly in mind, therefore, that a dividing line exists between the pure and impure clays and that any treatment to which both classes are subjected does not necessarily produce the same effect.

\section{THE PREHEATING TREATMENT}

In studying the effect of heat upon the clays selected for this work it was thought advisable to do this by means of the determination of the volume shrinkages, since the condensation in volume on drying is preeminently the characteristic phenomenon of this process. In practical work clays which dry too difficultly, due to an excessive amount of highly plastic matter, are found to become normal on reducing the shrinkage, for it is evident that the magnitude of the strain to which clays are subjected is a function of the diminution in volume, since it measures the amount of readjustment which must take place.

The objection to making comparisons of the volume shrinkage is that there is no standard consistency of the clay from which to start, so that the amount of water to be used in making up the clays depends upon the judgment of the operator. Various methods for deternining the consistency of plastic clay bodies have been proposed, such as the use of the Vicat needle, but none 
of them give an accuracy greater than that obtained by the "feel" of the clay in manipulating. As has been pointed out before, the proper consistency is fairly sharply defined and any excess or deficiency in water is at once noticed by the expert operator. In the nature of the case, however, slight variations in the water content are unavoidable, especially in working with a material as heterogeneous as clay, of which perfectly uniform samples are difficult to prepare.

In carrying out the preheating experiments a sample of clay sufficient in amount for making all of the test pieces of the series was thoroughly worked and tempered and kept at least 48 hours in a large desiccator containing water, so as to establish conditions of equilibrium. Cylindrical test pieces for the determination of the normal volume shrinkage were then made up and their volume measured as described above. These specimens were then dried to constant weight at $60^{\circ} \mathrm{C}$, and finally at $100^{\circ}$. Pats of clay of sufficient size were then removed from the bulk sample in the moist dessicator and dried to the following temperatures in a copper laboratory oven: I5O, 200, 250, 300, 350, and $400^{\circ} \mathrm{C}$, which were maintained for three hours. The dry pat resulting for each temperature was ground through a 20-mesh sieve and made up with water to its best plastic consistency. In one series of experiments these wet pats were kept over water for I 6 hours, in another series for one hour. After this period the moist clay was made up into cylindrical test pieces, the volume of which was found at once. The specimens were then dried and their volume again determined. In addition to the volume both the wet and the dry weights of the test pieces were obtained. During the weighing the specimens were kept in tightly closed tin cylinders.

(a) Effect upon Drying Shrinkage.-The specific gravities of the normal as well as of the preheated clays in the powdered condition were carefully determined by means of the pycnometer.

The preheating oven consisted of a cylindrical, air-jacketed vessel of heavy copper, 6 inches in diameter and 5 inches deep inside, the air space being I inch. The cover likewise was provided with an air space and had three tubulatures for the insertion 
of mercury thermometers. The heat was applied by a gas burner and the temperature regulated so that it did not vary on the average more than $5^{\circ}$ from the desired point.

In working up the ground, preheated clays into the plastic state it was at once observed that the amount of water required decreased with the increasing temperature treatment, although

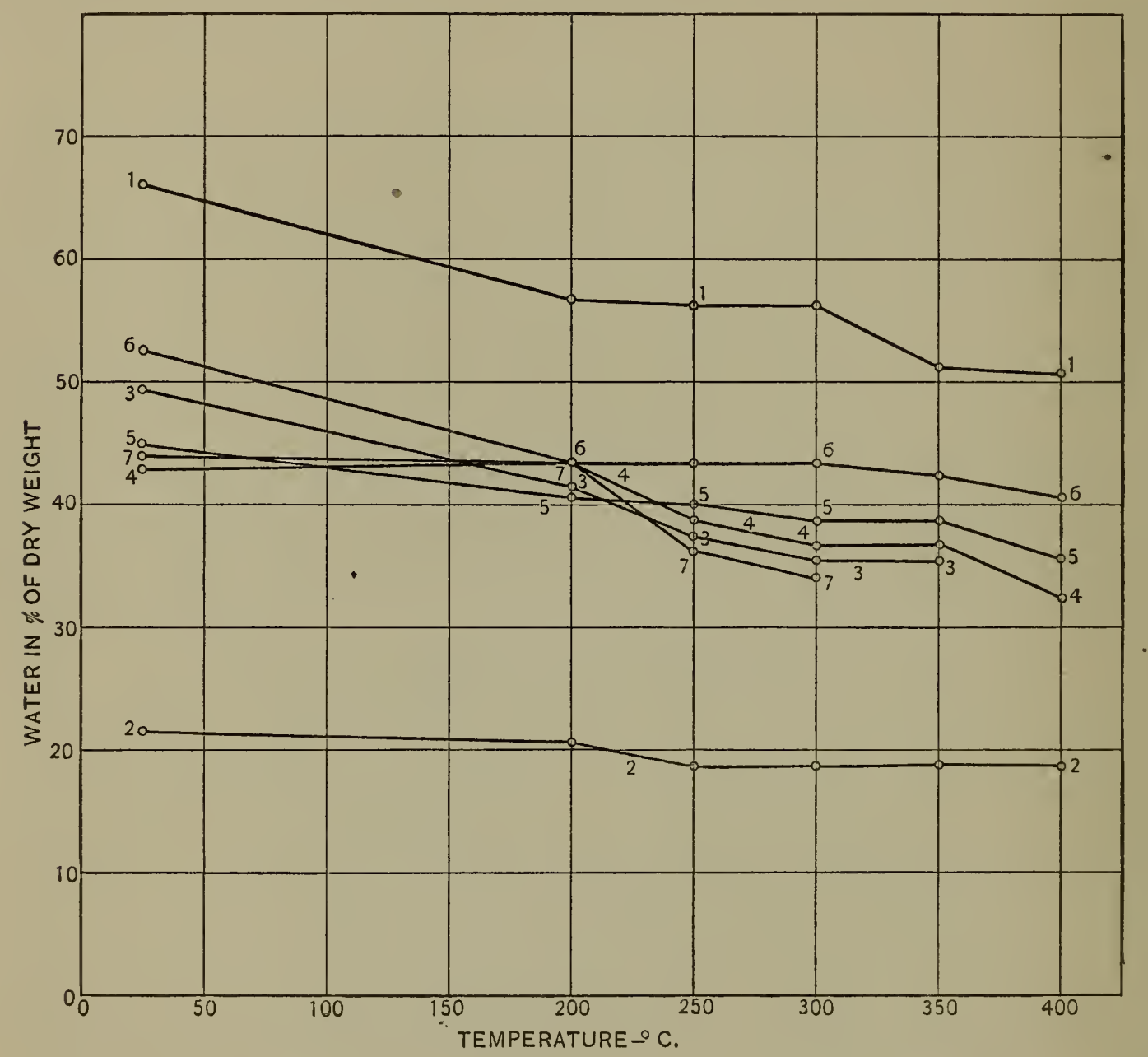

Fig. 4.-Variation in water content for clays preheated to different temperatures.

not in a regular manner, as shown by the curves of Fig. 4, representing seven clays. It appears from the diagram that the drop in the amount of water required is greatest between 200 and $300^{\circ}$ with most clays, although there are two exceptions in which this occurs at a higher temperature.

Owing to the fact that, independent of the slight variations in the molding, the amounts of shrinkage and pore water and hence 
the exterior volumes of the test pieces were not proportionately constant during these experiments, it was decided to express the volume shrinkages in terms of the true clay volume, i. e., the weight of the dried clay divided by its specific gravity, as has been shown before.

The decrease in volume shrinkage thus expressed is shown for the I 4 clays examined in Figs. 5 and 6.

The red-burning clays, it is observed, show four types of materials. The first class, represented by No. I, the excessively plastic material from Fort Pierre, N. Dak., which resembles bentonite in its behavior, evidently stands for abnormal clays, clearly beyond the limits of the workable kinds. It shows an abrupt decrease in the shrinkage curve, beginning at $250^{\circ}$, and continues to lose at a somewhat diminished rate up to the maximum temperature employed. Its final shrinkage still remains so high that no mistake is made by calling this clay hopeless from the standpoint of its commercial use.

In the second class again only one material is represented, No. 13 , a reddish-burning clay of the type of the so-called No. 2 fire clays. Its shrinkage loss curve is gradual, being most marked between 350 and $400^{\circ}$. This material being more homogeneous in structure and higher in clay matter than the average red burning clay seems to lose its plasticity more gradually, which differentiates it sharply from the other clays.

The third class of clays includes the average, highly plastic and frequently "sticky" clays of glacial or alluvial origin. The material losing its plasticity most abruptly is from an alluvial deposit. In practically all of them the most significant change took place between 250 and $300^{\circ}$.

In the fourth class we find one fine-grained material of glacial origin, evidently very high in nonplastic matter, which behaves very much like the other clays of the third group, differing only in its low initial shrinkage. It likewise seems to undergo its greatest change between 250 and $300^{\circ}$.

All of the clays, after showing their greatest drop in shrinkage, appear to change in color, assuming a reddish tinge and at the same time become granular. Finally, excepting clay No. I, they 


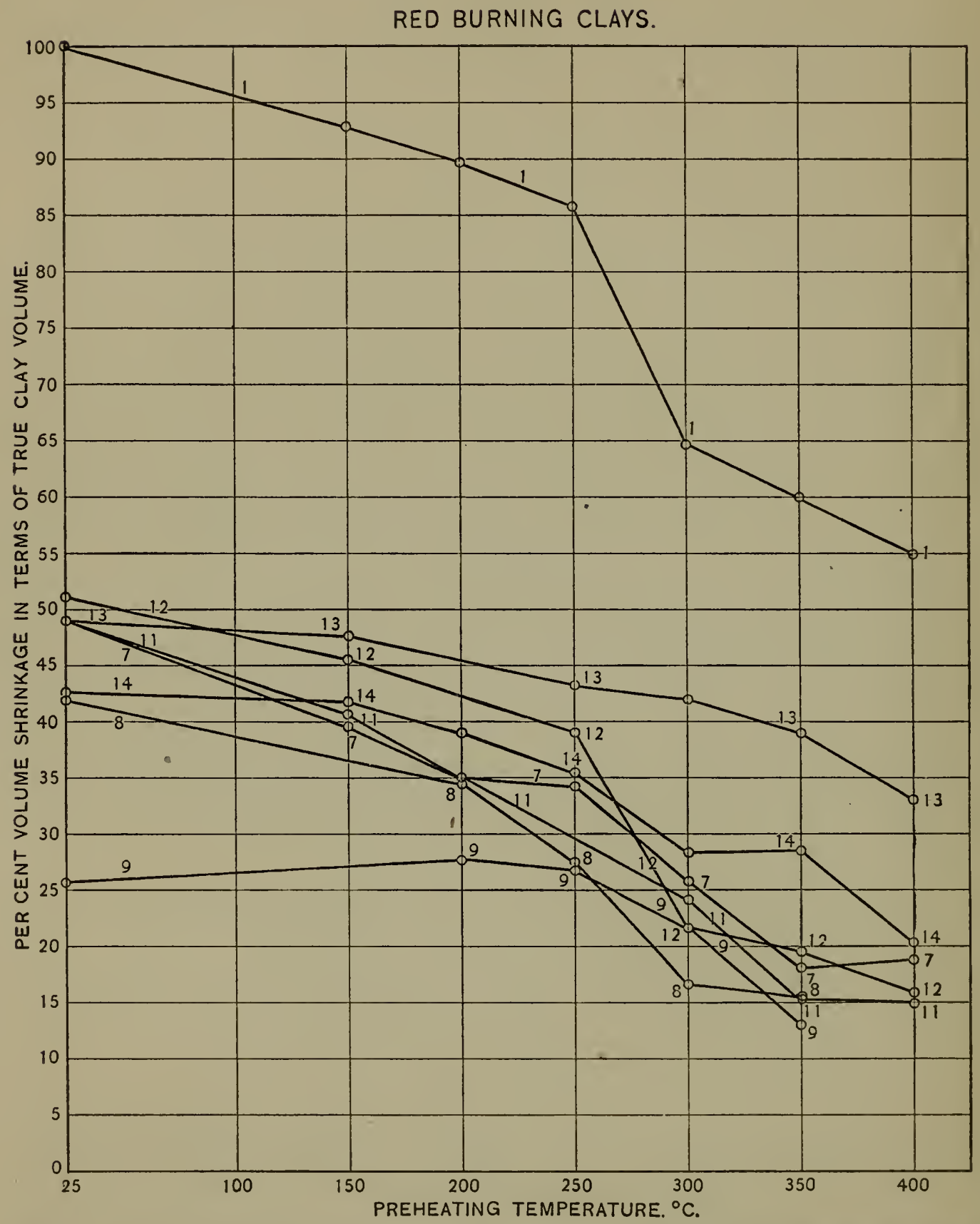

Fig. 5.-Volume shrinkage of red burning clays, preheated to different temperatures, made again plastic with water and dried at $60^{\circ} \mathrm{C}$. 
LIGHT BURNING CLAYS.

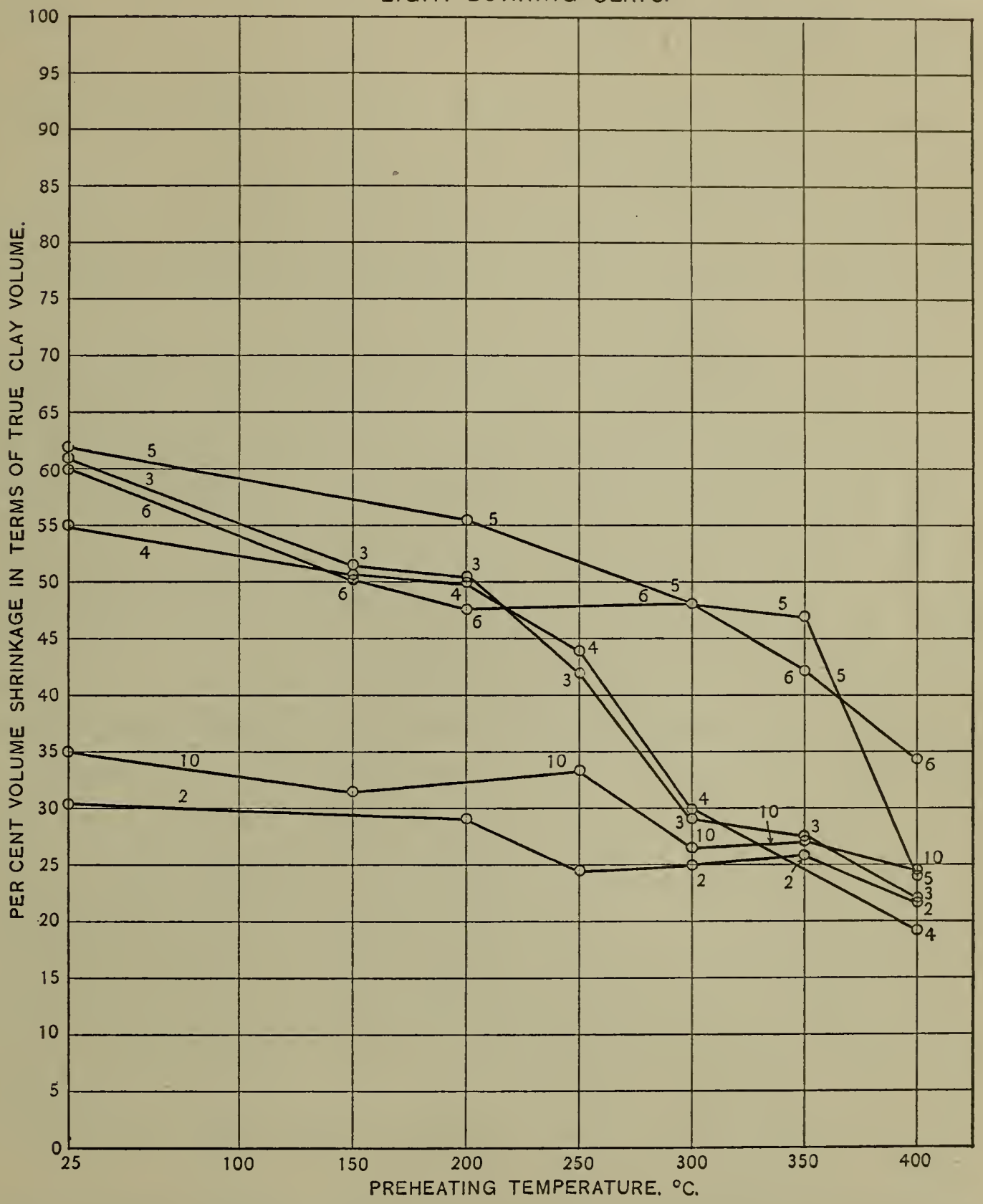

Fig. 6.-Volume shrinkage of light burning clays, preheated to different temperatures, made again plastic with water and dried at $60^{\circ} \mathrm{C}$. 
appear to be sand like and more or less inert in the presence of water. Up to $35^{\circ}$ the absorption of water takes place with great eagerness and a sensible amount of heat is evolved.

In the diagram representing the light-burning clays three groups may be recognized:

The first, with only one member, No. 5, an English ball clay, appears to lose plasticity gradually up to a certain point, $350^{\circ}$, when it shows a sudden drop.

In the second group, composed of Nos. 3, 4, and 5, the loss throughout is fairly gradual, although a more abrupt change is clearly observable between $25^{\circ}$ and $300^{\circ}$, and in the case of No. 6 , at $300^{\circ}$.

The third group evidently comprises the less plastic clays, which with a low initial shrinkage do not appear to have suffered any great changes, although even here No. Io, the English koalin, seems to have been impaired in plasticity at the same temperature as the other clays, $250-300^{\circ}$.

Like the red-burning clays, these materials become granular after the heating treatment and, according to their content of ferric oxide, assume a pink or gray color.

(b) Rate of Drying.-From the practical standpoint it seemed important to determine whether preheating had any effect upon the rate of drying. For this purpose eight clays were made up into cylinders of the same initial size and dried in a water-jacketed oven, at a constant temperature of $60^{\circ}$. The specimens were removed every hour and weighed. In every case it was found that the rate of drying of the preheated clays was identical with that of the normal materials, though, of course, the amount of water required to develop plasticity differed in the preheated materials from the normal amount. In Fig. 7 the curves of clay No. I are presented which are typical for all of the materials tested and show clearly that preheating does not influence the rapidity of drying.

In order to establish the rate of drying a clay in the raw and the preheated state under conditions permitting only of slow evaporation, a 200-pound sample of so-called swamp clay, very difficult to dry, was used. One-half of the sample was made up into $3 \cdot 5$-inch cubes on a small auger machine in the raw condition. 
The other half was preheated to $250^{\circ} \mathrm{C}$. before being made up into test pieces of the same dimensions. Of these, three cubes made from the raw and three from the preheated clay were selected and placed in a closet, maintained at room temperature,

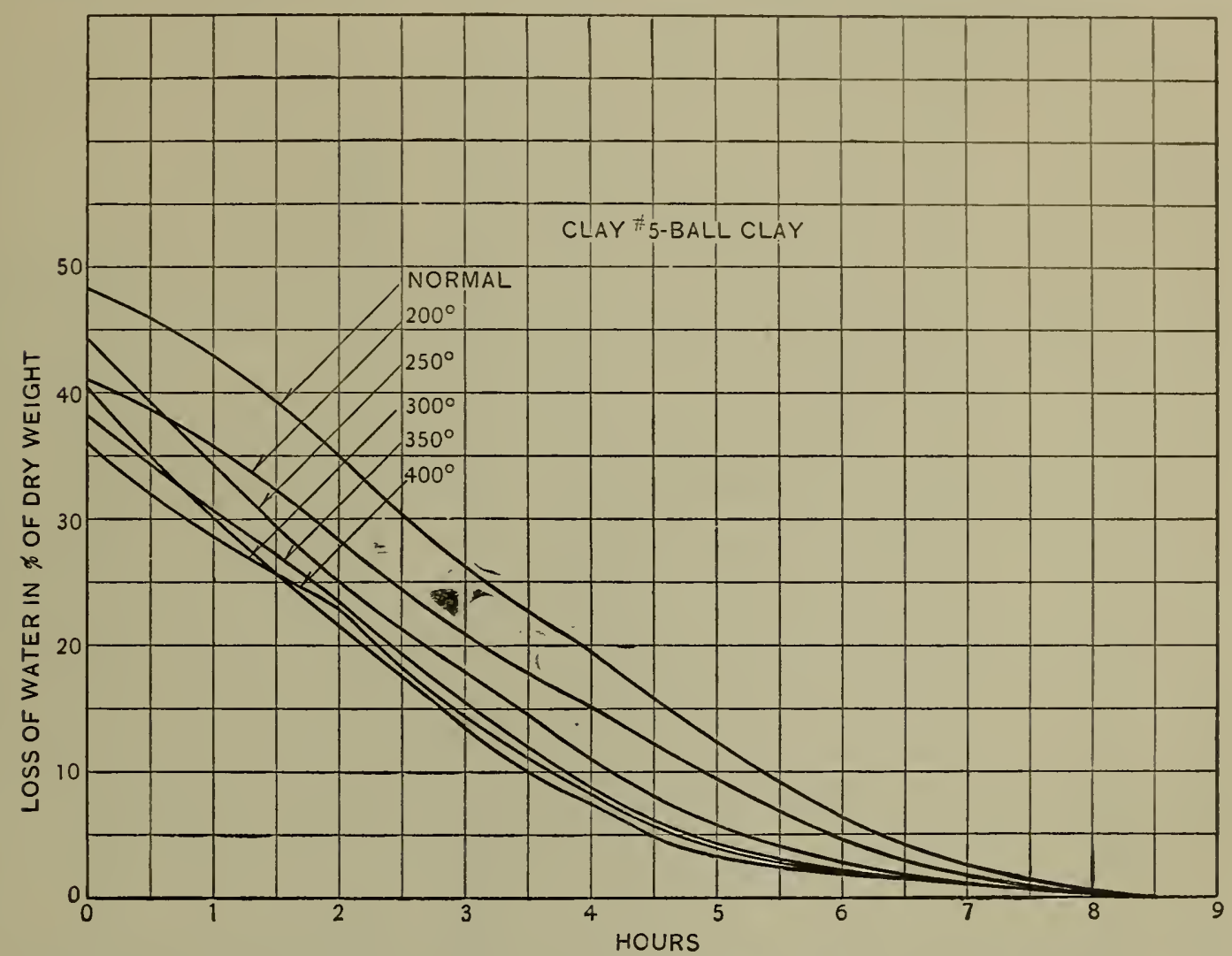

Fig. 7.-Rate of drying of clay, preheated at different temperatures, again made plastic with water and dried at $60^{\circ} \mathrm{C}$., compared with rate shown by the untreated clay.

as close together as possible and their weights determined at intervals. In Fig. 8 the curves representing the loss of water of these specimens are shown, and it is seen that the rate of evaporation of the preheated clay approaches closely that of the raw material.

\section{THE PRACTICAL EFFECT OF PREHEATING}

In the experiments just described it has already been shown that preheating has decreased the drying shrinkage. From this it might fairly be assumed that clays should dry more easily in the preheated than in the raw condition.

Experimental proof of this fact was obtained by working up batches of about five hundred pounds each of seven clays, both 


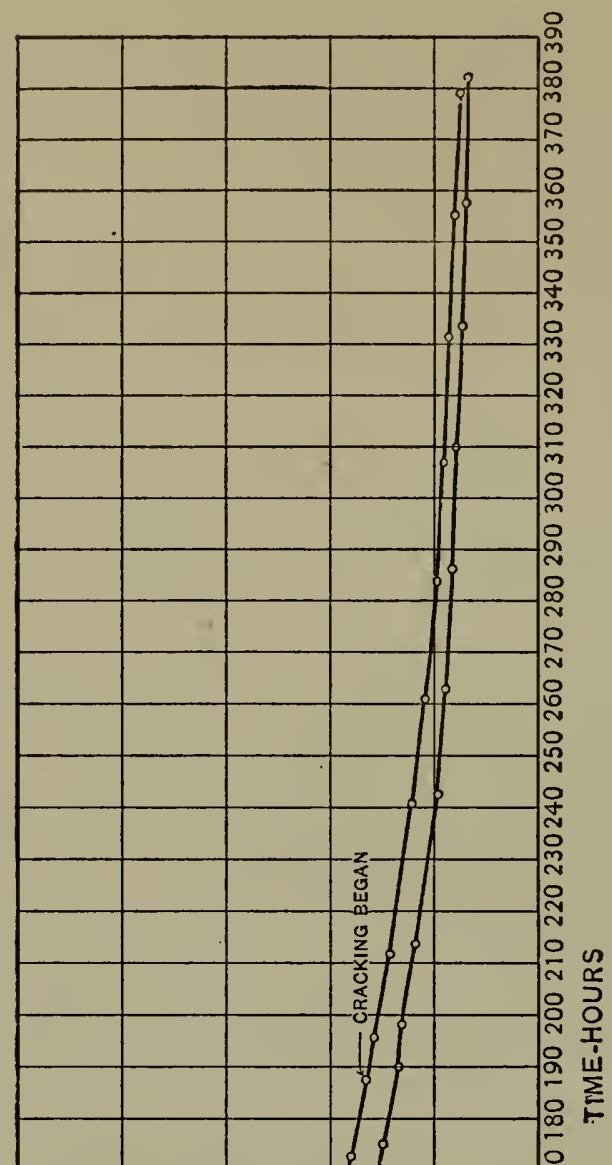

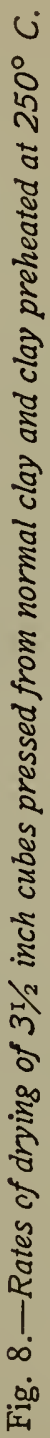

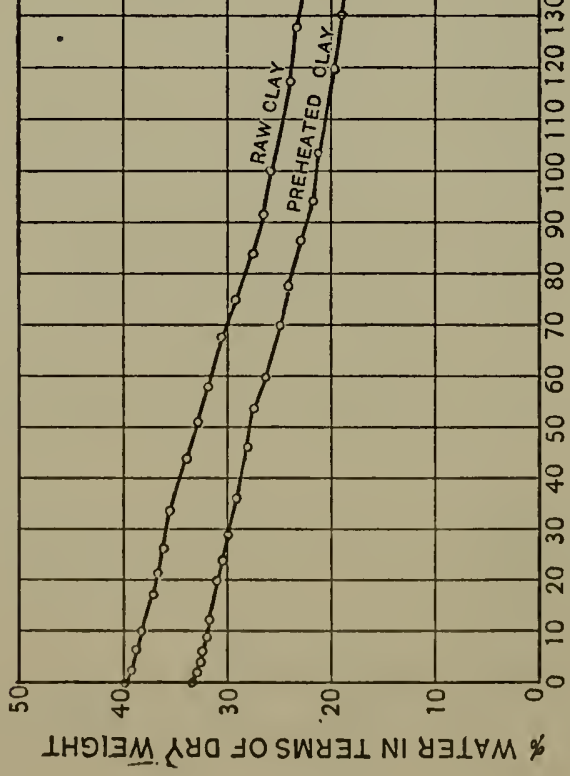


in the raw and in the preheated condition to the plastic state and putting them through an auger machine of commercial size. The clays were of the red burning type as employed in brick making, and were obtained from the following localities: Albert Lea, Minn., Heron Lake, Minn., Urbana, Ill., Peoria, I11., Groveport, Ohio, Athens, Ohio, and a so-called swamp clay from Curtice, Ohio.

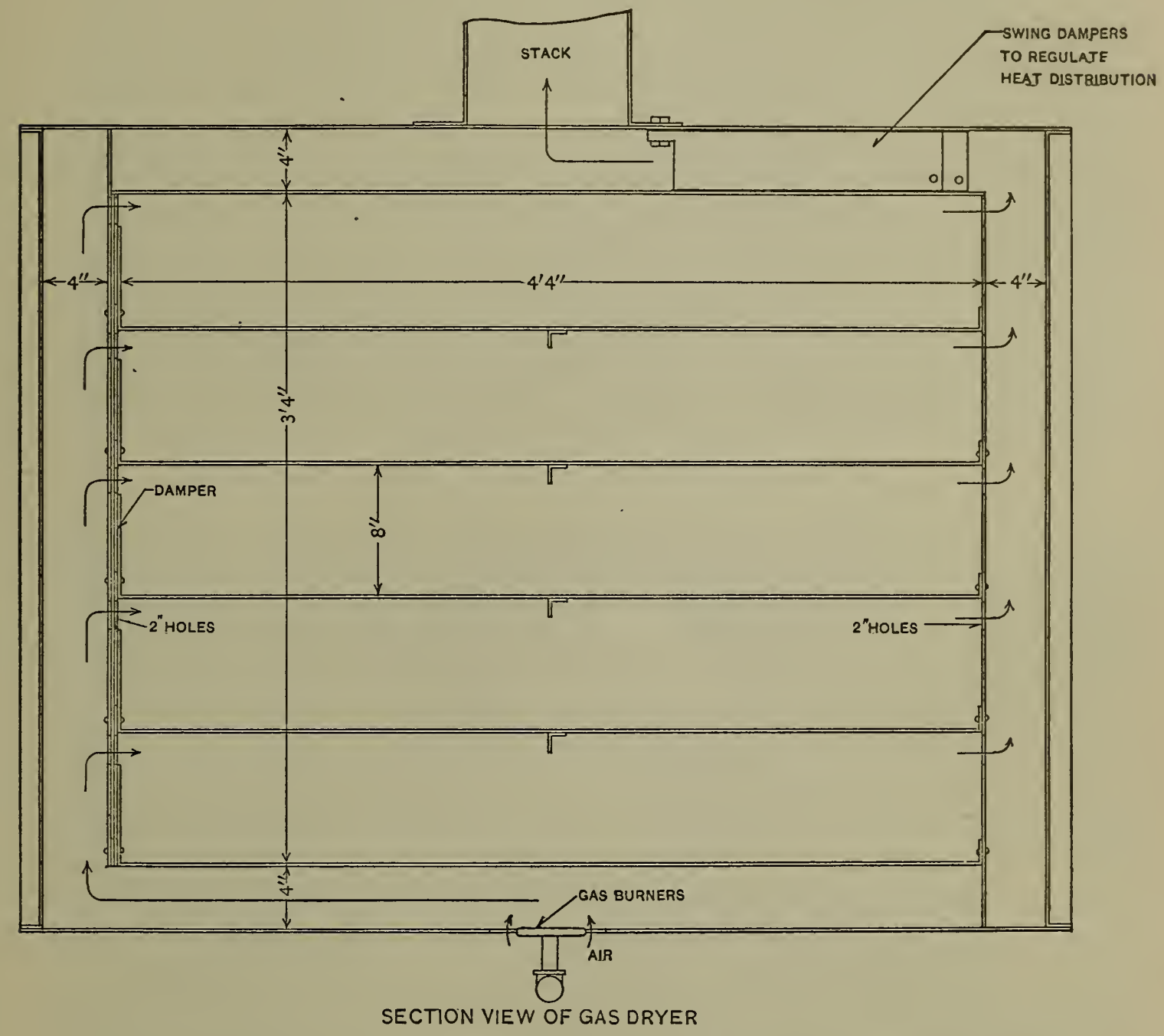

Fig. 9.-Diagram of gas-fired drying oven used for preheating larger quantities of clay.

The clay samples were preheated in a specially constructed sheet-iron oven fired with gas (Figs, 9 and ro), in which the heat distribution permitted of close regulation. This is accomplished by carrying the gases under the bottom plate up a collecting space on one side, from which they are distributed to each compartment. The admission of the heated air to each space 
is regulated by means of a grid sliding damper. At the exit sides of the oven the gases are again collected in a flue of the width of the oven and taken to the top, where they are removed through a central opening into the stack. In the double space on top through which the gases are removed, two hinged dampers are provided for throwing the heat to either side to compensate for the radiation losses on the front and back sides of the oven. Through tubulatures thermometers are inserted for controlling the temperature. After proper damper adjustment was made it was possible to keep the temperature constant within several degrees, assuring an accuracy ample for the purpose of the work. The preheating temperature adopted was $250^{\circ} \mathrm{C}$ and the time of drying six hours.

The raw clays were tempered in a wet pan, while the preheated materials were ground dry, screened through a piano-wire screen, and then made plastic in the pan. After tempering, the clay was taken to the auger machine (Fig. II), and pressed through a nonlubricating die into a round column $3 \frac{1}{2}$ inches in diameter. The cylindrical bar was cut up into discs $\mathrm{I} / 2$ inches thick, which were dried and their volume shrinkage noted. It was found in this connection that while the working behavior of two clays was decidedly improved by preheating, the others showed the need of lubrication, which it was impossible to provide. The result was that the test specimens were produced under conditions of strain.

In drying, it was found that one material, the clay from Heron Lake, Minn., cracked neither in the raw nor the preheated condition. Of the remaining six clays, in every case the discs made from raw clay cracked more or less badly, while those made from the preheated clay did not crack at all. The drying losses are compiled in Table VI. The number of test specimens made varied from 60 to Ioo, and for this reason the percentages expressing the drying loss are not of equal value.

It was observed especially on two preheated clays, the ones from Peoria and Groveport, that drier efflorescence was quite marked. From this it would appear that preheating releases the soluble salts such as the sulphates of potash, soda, lime, and magnesia contained in the clay, which, on the evaporation of the water, are carried to the surface and give rise to the discoloration 


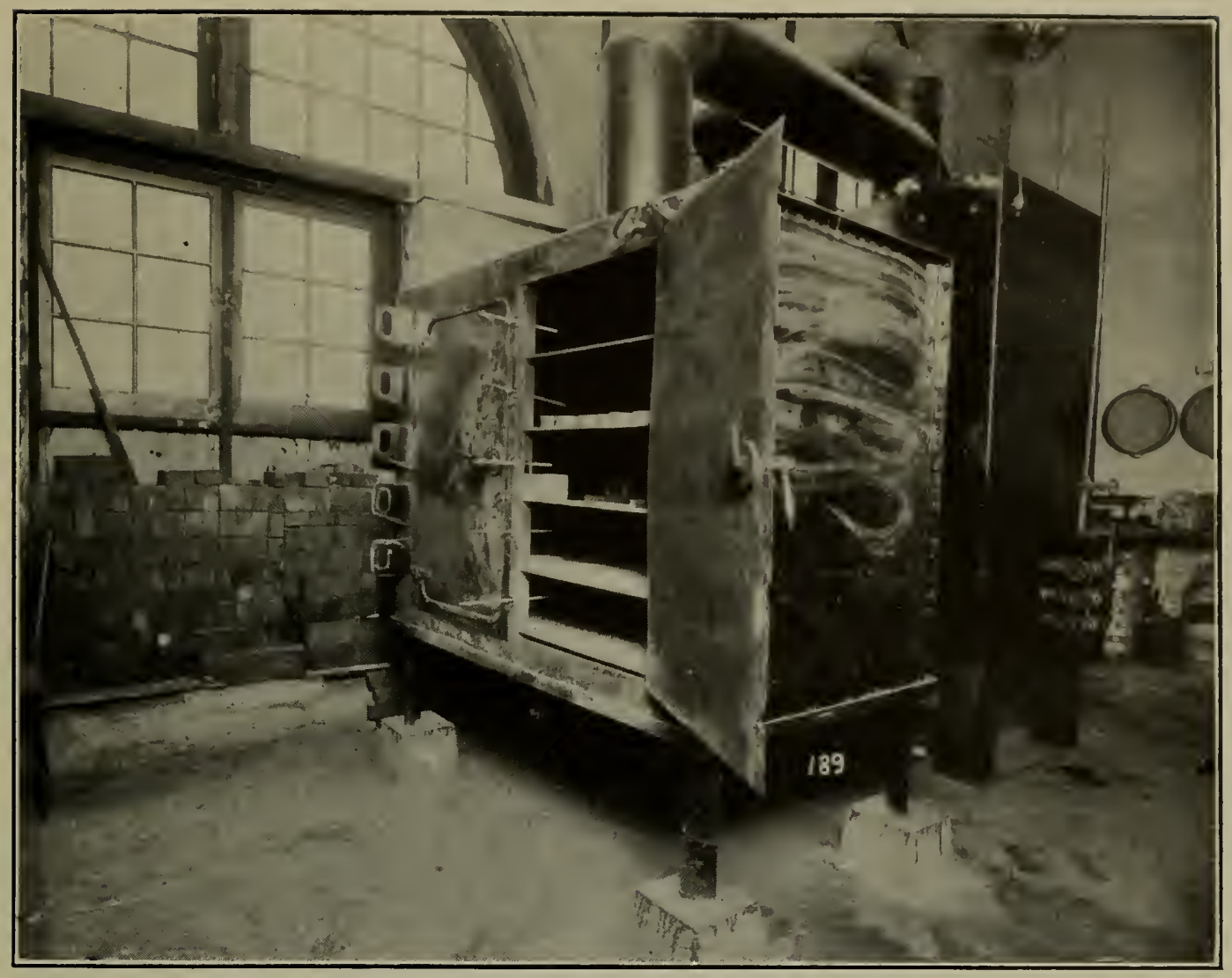

Fig. 10.-View of Preheating Oven.

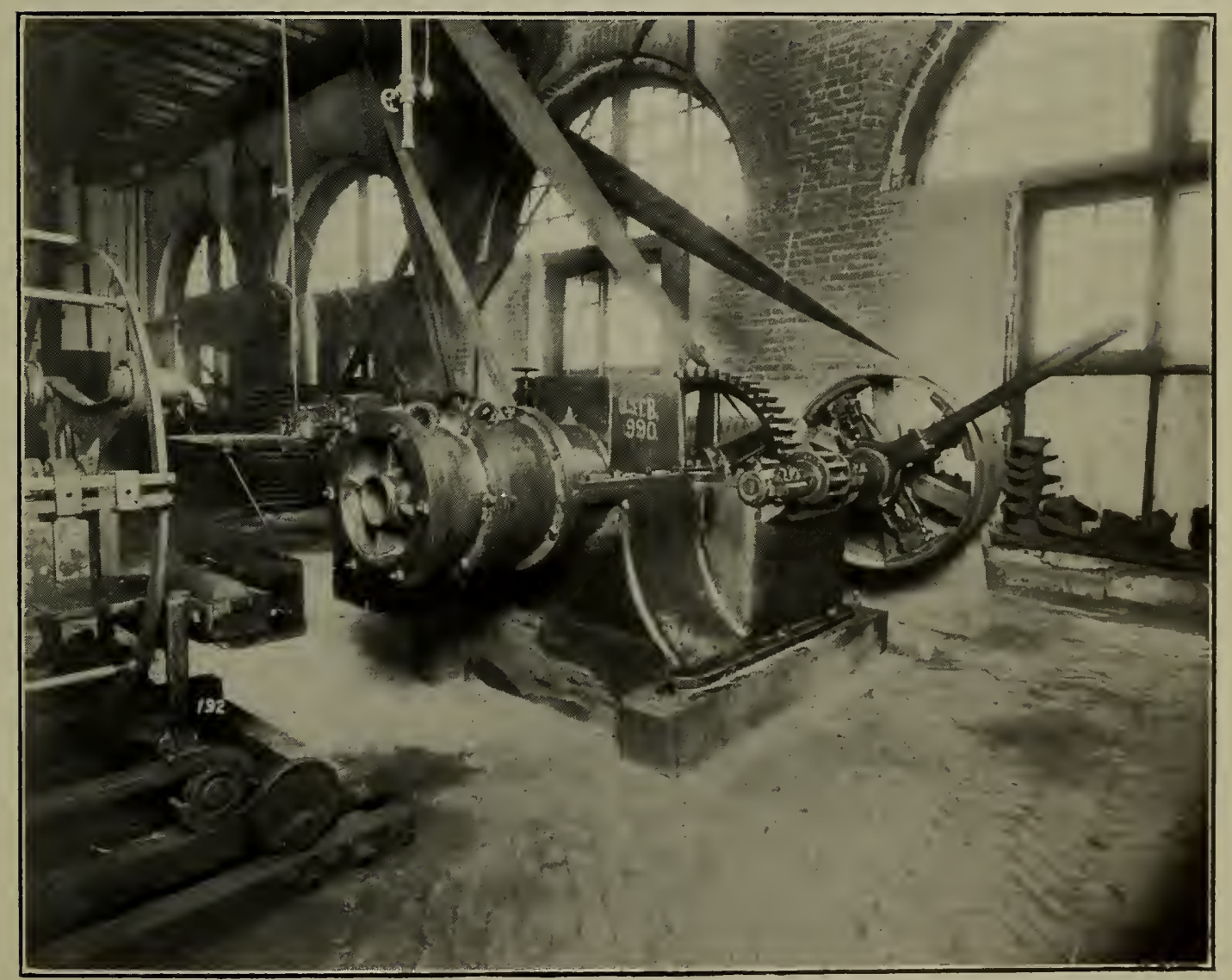

Fig. 11.-View of A uger Machine. 
commonly known as "white wash." The adsorbing power of clay thus seems to be diminished by this treatment, and in some clays the resulting discoloration might prohibit their use for the manufacture of face brick and similar products. It was evident, however, that this effect varied with the character of the clay, its physical structure, and its content of soluble salts, and hence can not be considered a necessary result in every case.

\section{TABLE VI}

Percentage Drying Loss

\begin{tabular}{|c|c|c|c|}
\hline Clay & $\begin{array}{l}\text { Per cent dry- } \\
\text { ing loss of test } \\
\text { pieces made } \\
\text { from raw clay }\end{array}$ & $\begin{array}{l}\text { Per cent dry- } \\
\text { ing loss of } \\
\text { test pieces } \\
\text { made from } \\
\text { preheated clay }\end{array}$ & Remarks \\
\hline Albert Lea, Minn. . & 95 & 0 & \\
\hline Heron Lake, Minn & 0 & 0 & \\
\hline Urbana, Ill......... & 90 & 0 & Repeated with clay preheated to $300^{\circ}$ \\
\hline Peoria, Ill ......... & 95 & 0 & Repeated with clay preheated to $300^{\circ}$ \\
\hline Groveport, Ohio.... & 100 & 0 & Repeated with clay preheated to $300^{\circ}$ \\
\hline Athens, Ohio..... & 100 & 0 & \\
\hline Curtice, Ohio.... & 100 & 0 & \\
\hline
\end{tabular}

7. THE CAUSE OF THE IMPROVEMENT IN THE DRYING BEHAVIOR DUE TO PREHEATING

It has thus been shown beyond doubt that the drying of excessively plastic clays is facilitated by preheating, that evidently the resistance to the capillary flow has been decreased so that the difference between the amount of water evaporated from the surface per unit time and that supplied from the interior of the clay mass is no longer great enough to cause strains which lead to checking.

There remains now the task of determining the cause of this improved condition.

This part of the problem was attacked by means of the following methods: I. Determination of the specific gravity of the clays preheated to different temperatures. 2. Mechanical analysis of the normal and preheated clays. 3. Determination of the adsorbing power of normal and preheated clays from malachite green in solution. 4. Determination of the distribution of shrinkage and pore water. 
Specific Gravity: In these experiments a pat of plastic consistency weighing about a pound was made up of each clay which was cut up into smaller lumps for preheating at the different temperatures. The preheating was done in the small drying ovens referred to above. The preheated specimens were then crushed and passed through a 6o-mesh sieve. By means of the pycnometer the specific gravity of each sample was determined, care having been taken to eliminate the inclosed air by connecting up the specific gravity bottle to a suction pump and heating in warm water up to the boiling point. Ample time was allowed for cooling in running water and the final temperature of the liquid in the pycnometer was taken into account. It was found that the specific gravity of the clays differed even in the same lump, and it proved difficult to bring about the desired homogeneity of the sample. The results of these determinations are given in Table VII. Though the irregularity in the results is evident, it is

TABLE VII

Specific Gravity of Clays

\begin{tabular}{r|c|c|c|c|c|c|c}
\hline $\begin{array}{c}\text { No. } \\
\text { Clay }\end{array}$ & Normal & $150^{\circ}$ & $200^{\circ}$ & $250^{\circ}$ & $300^{\circ}$ & $350^{\circ}$ & $400^{\circ}$ \\
\cline { 1 - 4 } 1 & 2.451 & 2.456 & 2.630 & 2.603 & 2.603 & 2.657 & 2.621 \\
2 & 2.537 & 2.548 & 2.636 & 2.612 & 2.609 & 2.644 & 2.647 \\
3 & 2.577 & 2.591 & 2.600 & 2.600 & 2.590 & 2.593 & 2.590 \\
4 & 2.596 & 2.589 & 2.646 & 2.629 & 2.629 & 2.664 & 2.664 \\
5 & 2.560 & 2.560 & 2.550 & 2.605 & 2.601 & 2.600 & 2.600 \\
6 & 2.510 & 2.512 & 2.562 & 2.545 & 2.556 & 2.580 & 2.573 \\
7 & 2.510 & 2.490 & 2.648 & 2.638 & 2.627 & 2.653 & 2.665 \\
8 & 2.603 & 2.621 & 2.653 & 2.650 & 2.655 & 2.692 & 2.696 \\
9 & 2.784 & 2.741 & 2.728 & 2.725 & 2.721 & 2.747 & 2.751 \\
10 & 2.476 & 2.560 & 2.605 & 2.639 & 2.638 & 2.637 & 2.644 \\
11 & 2.575 & 2.587 & 2.649 & 2.650 & 2.645 & 2.676 & 2.697 \\
12 & 2.680 & 2.707 & 2.709 & 2.729 & 2.769 & 2.732 & 2.696 \\
13 & 2.768 & 2.739 & 2.701 & 2.761 & 2.820 & 2.825 & 2.773 \\
14 & 2.645 & 2.666 & 2.684 & 2.712 & 2.662 & 2.743 & 2.708 \\
\hline
\end{tabular}

seen that all but one clay show a noticeable increase in specific gravity due to preheating which must be ascribed in part to the expulsion of the small quantity of hygroscopic water held so persistently and in part to a condensation of the specific volume of the clay. Since it is not likely that the crystalline constituents have suffered any such change at the temperatures involved we must conclude that the effect is confined to the nongranular clay matter. The contraction in volume might be explained by the 
closing up or shrinkage of the assumed colloidal matter very similar to the contraction of the silicic acid gel and other substances of like character. It is evident that this condensation would involve only the minute, micellean structure of the material and does not refer to the capillary system of the clay aggregate. In making up the preheated clays with water it was observed that some heat was given off. It was thought to be interesting to determine approximately the amount of heat thus evolved from a normally dried clay and a preheated material. For this purpose a sample of a red plastic surface clay was divided into two parts. One was dried at $105^{\circ} \mathrm{C}$, the other was heated to $300^{\circ}$. By placing weighed amounts of the clay into an improvised calorimeter, adding a known amount of water and noting the temperature rise by means of a corrected thermometer reading to $\mathrm{I} / 50^{\circ}$ the heat given off by the clay dried at $105^{\circ}$ was found to be almost 4-gram calories and that by the preheated material practically 5 calories per gram.

Mechanical Analysis: In determining the changes brought about by preheating as regards the fineness of grain, four samples of clay were prepared by thoroughly mixing them and dividing each portion into two parts. One half was preheated to $300^{\circ} \mathrm{C}$ and then put through the Schulze apparatus, the other was run through in the normal condition. The results are compiled in Table VIII. In carrying out this work it became at once evident that the preheated clays showed an extraordinary tendency to form aggregate particles in spite of the fact that they were first mechanically shaken in water and apparently deflocculated by the use of $\mathrm{NaOH}$ and $\mathrm{Na}_{2} \mathrm{C}_{2} \mathrm{O}_{4}$ solutions. These particles were found to be so hard that they could not be worked through the sieves by simple rubbing. The results show that for this reason the clays have become decidedly coarser, the surface factor having been decreased. This applies not only to the sieve sizes, but also to the sizes separated by the first two cans. This difference between the normal and the preheated clays appears to be due to coagulation, the fine individual particles forming aggregates of varying sizes. From this it follows that a decided change in the capillary structure of the clay must have been brought about tending either to increase or decrease the pore space. Just in what direction this change proceeds will be shown later. 


\section{TABLE VIII}

Mechanical Analysis

NORMAL AND PREHEATED CLAYS

\begin{tabular}{|c|c|c|c|c|c|c|c|c|c|}
\hline \multirow{2}{*}{ Clay } & \multirow{2}{*}{40} & \multirow{2}{*}{60} & \multirow{2}{*}{80} & \multirow{2}{*}{100} & \multirow{2}{*}{120} & \multicolumn{3}{|c|}{ Cans } & \multirow{2}{*}{$\begin{array}{l}\text { Over- } \\
\text { flow }\end{array}$} \\
\hline & & & & & & 1 & 2 & 3 & \\
\hline $\mathbf{N}$ & 0.84 & 1.77 & 1.33 & 3.78 & 0.20 & 8.02 & 15.12 & 2.21 & 66.72 \\
\hline $\mathrm{G}^{1} 300^{\circ}$ & 4.04 & 5.76 & 2.42 & 7.08 & 0.39 & 16.90 & 16.28 & 3.00 & 44.13 \\
\hline $\mathbf{N}$ & 1.96 & 1.80 & 1.50 & 3.37 & 0.16 & 4.07 & 4.45 & 2.32 & 80.37 \\
\hline $\mathbf{A}^{2} 300^{\circ}$ & 4.56 & 2.66 & 1.96 & 1.33 & 0.22 & 5.47 & 8.38 & 5.01 & 70.40 \\
\hline $\mathbf{N}$ & 1.11 & 1.37 & 0.58 & 0.70 & 0.15 & 2.79 & 26.56 & 5.07 & 61.66 \\
\hline $\mathbf{S}^{3} 300^{\circ}$ & 9.54 & 9.28 & 3.26 & 2.20 & 0.10 & 5.74 & 37.25 & 4.39 & 28.23 \\
\hline $\mathbf{N}$ & 0.30 & 0.40 & 0.34 & 0.50 & 0.08 & 0.83 & 3.84 & 6.18 & 87.52 \\
\hline $\mathrm{H}^{4} 300^{\circ}$ & 3.71 & 2.77 & 0.71 & 1.99 & 0.33 & 3.29 & 5.57 & 4.44 & 77.17 \\
\hline
\end{tabular}

1 Alluvial clay, Groveport, Ohio. ${ }^{2}$ Impure No. 2 fire clay, Athens, Ohio. ${ }^{3}$ Joint clay, Urbana, Ill. 4 Glacial clay, Heron Lake, Minn.

Malachite Green Adsorption: H. E. Ashley ${ }^{12}$ employs the ability of clays to absorb complex organic salts, such as malachite green, from their solutions as a means of comparing the plasticity of different clays, and makes the assumption that, other things being equal, the more plastic a clay the more of the dissolved substance it takes out of solution. In casting about for a numerical factor expressing the plasticity of a clay, however, he found it necessary to introduce two modifying factors, drying shrinkage and fineness of grain, as expressed by the Jackson-Purdy surface factor. $\mathrm{He}$ thus arrives at the expression:

$$
P=\frac{C B}{A} \text {, where- }
$$

$P=$ numerical value proportional to plasticity.

$C=$ relative colloid content, based upon the amount of organic salt (malachite green) absorbed.

$B=$ per cent shrinkage of clay discs made by casting the lawned slip into plaster molds. $A=$ surface factor.

Ashley hence assumes that plasticity is proportional to the amount of malachite green adsorbed from solution and to the drying shrinkage and inversely proportional to the fineness. 
Since in connection with the present work the fact that plasticity has been decreased by the preheating treatment has been established beyond doubt, it was thought to be of interest to determine the differences in the absorption of malachite green by preheated clays. This work was done by Mr. H. E. Ashley, and consisted in shaking one gram of clay by mechanical means in IOO $\mathrm{cc}$ of a malachite green solution containing 0.3 gram of the dye. The amount of malachite green remaining in solution was determined colorimetrically. The value thus obtained was then expressed as the relative adsorption capacity of the different materials in terms of the adsorption shown by a standard plastic clay, the Tennessee No. 3 ball clay. The latter was assumed, therefore, to show a colloidal value of roo. A clay giving a value of 75 should then contain 75 per cent of the colloid matter present in the Tennessee clay. The results of these determinations are compiled in Table IX.

\section{TABLE IX}

Adsorption Factors of Normal and Preheated Clays

\begin{tabular}{c|c|c|c|c|c}
\hline Clay & $\begin{array}{c}\text { Surface clay, } \\
\text { Albert Lea, } \\
\text { Minn. }\end{array}$ & $\begin{array}{c}\text { Joint clay, } \\
\text { Urbana, Il. }\end{array}$ & $\begin{array}{c}\text { Joint clay, } \\
\text { Peoria, Ill. }\end{array}$ & $\begin{array}{c}\text { Alluvial clay, } \\
\text { Groveport, } \\
\text { Ohio }\end{array}$ & $\begin{array}{c}\text { Impure No. 2 } \\
\text { fire clay, } \\
\text { Athens, Ohio }\end{array}$ \\
\hline Normal................ & 600 & 142 & 175 & 104 & 160 \\
Preheated at 250 C.... & 475 & 137 & 150 & 106 & 140 \\
\hline
\end{tabular}

Inspection of these figures shows at once that, although in four out of the five cases the adsorption has been decreased, the difference is not in proportion to the difference in the physical behavior of the clays. It is evident, therefore, that, with the exception of the Minnesota clay, no decided change in structure is indicated by these tests. It would seem then that the partially irreversibly "set" gel shows the same adsorption as the reversible gel, and that the adsorption of malachite green, from its solution, does not appear to be any measure of plasticity, as far as these preheated clays are concerned.

Distribution of Shrinkage and Pore Water.-From the results of the mechanical analyses of the normal and preheated clays, as well as from direct observation made during the course of the $7 \mathrm{II} 32^{\circ}-\mathrm{II}-4$ 
shrinkage experiments, it became evident that the amount of pore water in the preheated clays differed from that present in the normal materials. It hence was found necessary to determine the amounts of shrinkage and pore water present in the same clay after heating it to different temperatures. This was done similarly to the previous calculations of the drying shrinkage expressed in terms of the true clay volume. These results are collected in Table X.

\section{TABLE X}

Distribution of Shrinkage and Pore Water

\begin{tabular}{|c|c|c|c|c|c|c|c|c|}
\hline \multirow{2}{*}{ Clay } & & \multicolumn{7}{|c|}{ Per cent by volume in terms of true clay volume. } \\
\hline & & Normal & $150^{\circ} \mathrm{C}$ & $200^{\circ} \mathrm{C}$ & $250^{\circ} \mathrm{C}$ & $300^{\circ} \mathrm{C}$ & $350^{\circ} \mathrm{C}$ & $400^{\circ} \mathrm{C}$ \\
\hline $\begin{array}{l}\text { Alluvial clay, Groveport, } \\
\text { Ohio, No. } 12 \text {. }\end{array}$ & $\begin{array}{l}\text { Total water....... } \\
\text { Shrinkage water.. } \\
\text { Pore water....... }\end{array}$ & $\begin{array}{l}87.20 \\
51.09 \\
36.11\end{array}$ & $\begin{array}{l}30.52 \\
45.49 \\
35.03\end{array}$ & $\begin{array}{l}71.11 \\
37.61 \\
33.50\end{array}$ & $\begin{array}{l}73.00 \\
39.22 \\
33.78\end{array}$ & $\begin{array}{l}72.60 \\
21.70 \\
50.90\end{array}$ & $\begin{array}{l}74.60 \\
19.66 \\
54.94\end{array}$ & $\begin{array}{l}70.80 \\
15.98 \\
54.82\end{array}$ \\
\hline $\begin{array}{l}\text { Glacial surface clay, } \\
\text { Heron Lake, Minn., } \\
\text { No. 13. }\end{array}$ & $\begin{array}{l}\text { Total water........ } \\
\text { Shrinkage water.. } \\
\text { Pore water....... }\end{array}$ & $\begin{array}{l}95.20 \\
42.65 \\
52.55\end{array}$ & $\begin{array}{l}90.00 \\
41.80 \\
48.20\end{array}$ & $\begin{array}{r}92.60 \\
38.92 \\
53.68\end{array}$ & $\begin{array}{l}90.70 \\
35.37 \\
55.33\end{array}$ & $\begin{array}{l}84.30 \\
28.27 \\
56.03\end{array}$ & $\begin{array}{l}97.10 \\
31.17 \\
65.93\end{array}$ & $\begin{array}{l}84.40 \\
20.35 \\
64.05\end{array}$ \\
\hline $\begin{array}{l}\text { Impure No. } 2 \text { fire clay, } \\
\text { Athens, Ohio, No. } 14 .\end{array}$ & $\begin{array}{l}\text { Total water........ } \\
\text { Shrinkage water.. } \\
\text { Pore water....... }\end{array}$ & $\begin{array}{l}72.19 \\
49.05 \\
23.14\end{array}$ & $\begin{array}{l}78.06 \\
47.55 \\
30.51\end{array}$ & $\begin{array}{l}73.17 \\
47.43 \\
25.74\end{array}$ & $\begin{array}{l}70.33 \\
43.23 \\
27.10\end{array}$ & $\begin{array}{l}75.78 \\
49.06 \\
33.82\end{array}$ & $\begin{array}{l}71.60 \\
38.96 \\
32.64\end{array}$ & $\begin{array}{l}71.88 \\
33.34 \\
38.54\end{array}$ \\
\hline
\end{tabular}

For the sake of facilitating comparison the relations obtained are shown graphically in Figs. I 2, I3, and 14 .

Referring to Fig. I2, it is observed that with this clay a marked increase in the amount of pore water is shown between $250^{\circ}$ and $300^{\circ}$, and it is quite evident that the clay approaches the condition of an inert, nonplastic material as the shrinkage water decreases. The two curves will meet at the point at which the clay will have lost its plasticity. This increase in pore space shown brings out the fact that the preheating of clays causes them to become more porous, and it offers the explanation of the improved drying qualities of the materials thus tested. The increased pore space opens up the clay body, reduces the surface tension, and thus offers less resistance to the flow of water through the capillary system toward the end of the shrinkage when drying conditions are most severe. Owing to the smaller shrinkage it 


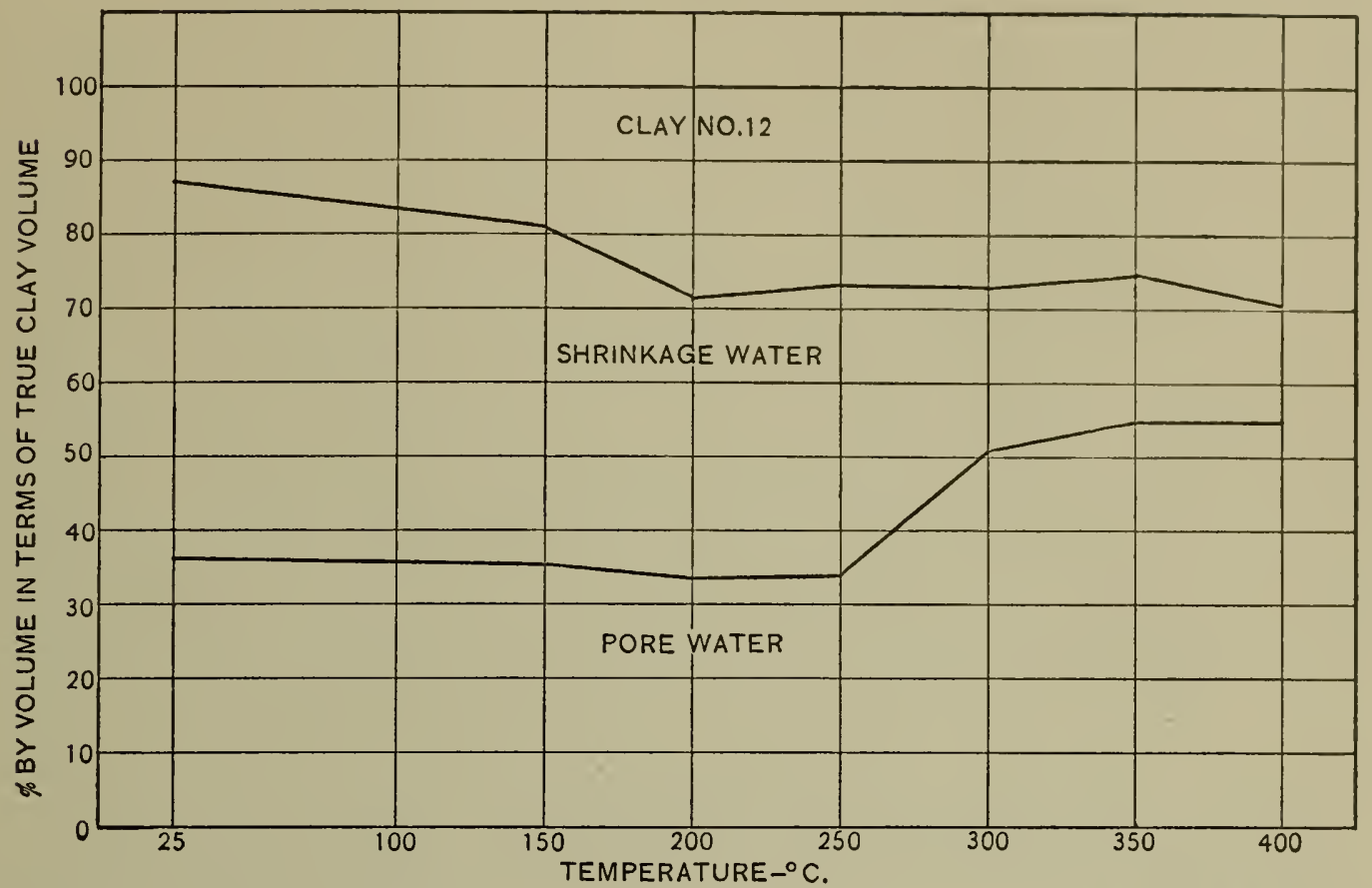

Fig. 12.-Relation of shrinkage to pore water of Groveport, O., clay preheated at different temperatures, again made plastic with water and dried at $60^{\circ} \mathrm{C}$.

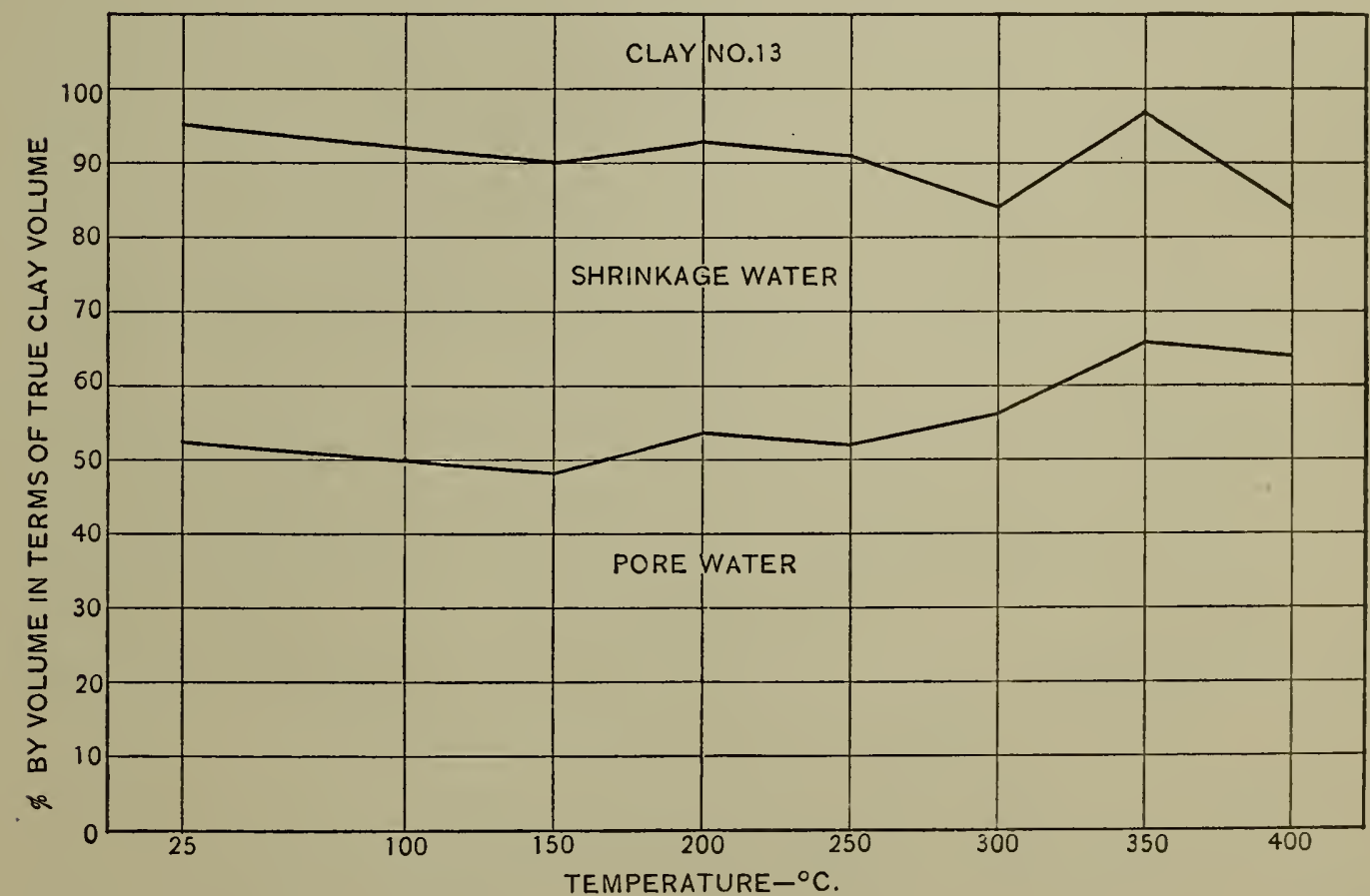

Fig. 13.-Relation of shrinkage to pore water of Heron Lake, Minn., clay preheated at differ. ent temperatures, again made plastic with water and dried at $60^{\circ} \mathrm{C}$. 
is evident that the total strain due to contraction is lessened. As has been shown above, however, the actual rate of evaporation from, for instance, two cubes of the same initial size, one consisting of raw and the other of preheated clay under the same conditions of temperature and humidity are about the same. This comparison is not quite fair, since the preheated clay cube would contain somewhat more weight of material than the other.

The clay represented by Fig. I3-a plastic, impure glacial clay-showed likewise a constant increase in the amount of pore water at the expense of the shrinkage water, but the change appears to be more gradual. The shrinkage water retained by the clay heated to $400^{\circ}$ still constitutes a large part of the total water, thus indicating that the residual plasticity is still considerable. This clay should be a safe material for preheating purposes.

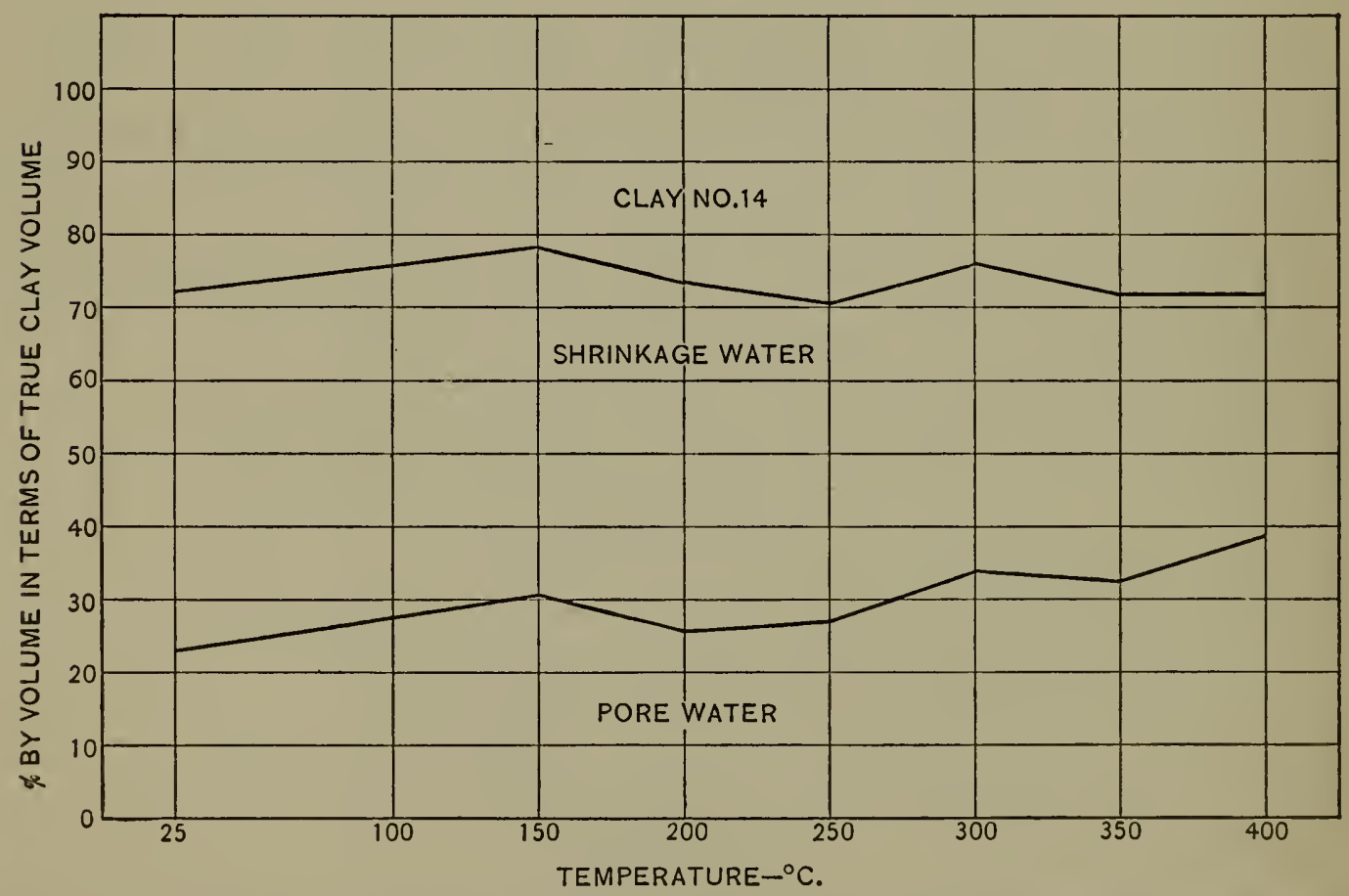

Fig. 14.-Relations of shrinkage to pore water of Athens, Ohio, clay, preheated at different temperatures, again made plastic with water and dried at $60^{\circ} \mathrm{C}$.

In Fig. I 4 the material, a fire clay, shows a decrease in shrinkage water between $300^{\circ}-400^{\circ}$ and a fairly high amount of shrinkage water at the highest temperature. It is evident that if preheating were necessary in this case the temperature could exceed $300^{\circ}$. 
From these illustrations it appears that the proper preheating temperature varies for different clays. While in certain materials the desired change to a more nonpiastic condition is brought about gradually it is abrupt in others. It is evident from this consideration that the permissible temperature range in the former case is considerably wider than for the latter, where an excessive temperature might carry the conditions too close to the inert state.

From the work done in the present study no general conclusions can be stated as to the behavior of all kinds of clay. As a broad proposition, it might be said that the more impure clays show as a rule a more abrupt change and more narrow temperature limits than the more homogeneous plastic clays of the No. 2 fire-clay or ball-clay types.

In regard to the time required for the preheating no attempt has been made to look into this matter, but it would appear from the present work that it is simply a question of transmitting the heat through the lumps of clay. The larger the average size of the clay lumps the longer should be the time allowed for the heating. From this it follows that it would be policy in commercial work to shred or cut up the material before introducing it into the drying apparatus. Under the conditions of practice the temperature of the rotary dryer is best maintained close to $500^{\circ} \mathrm{C}$, and the time of passage through the dryer reduced accordingly.

\section{THE EFFECT OF PREHEATING UPON THE MANUFACTURE OF CLAY PRODUCTS}

Since it has been shown by experiment that the pore space of preheated clays increases as the clay particles gradually assume the character of more or less inert, sand-like matter, the question arises whether it might not be possible that some clays, even though preheated at lower temperatures, would become too porous to be worked successfully by certain molding machines used in practice, due to the fact that the permissible limit of pore water had been reached. Under this condition might it not be that owing to the greater average distance between the particles the cohesive force would not suffice to hold the mass together if a larger amount of water is used than is necessary to bring the clay to the condition in which it is used in auger machines? 
This point was investigated by making up two preheated surface clays with a large amount of water to the consistency of the so-called "soft-mud" process and making them into bricks in regular wooden brick molds. It was found in both cases that the clays showed a decided tendency to "slump" and that they were too weak to withstand the drying strains, resulting in bad cracking and checking. The same preheated clays when worked on the auger machine dried without difficulty. This shows that the amount of water used in bringing such a clay to the plastic state must not be excessive. From this standpoint the auger-machine and dry-press process are to be preferred to the "soft-mud" method of molding.

In tempering preheated clay the point of proper stiff plastic consistency is defined more sharply than with the normal material. When the predried clay is worked in the auger machine it is important to provide the best lubrication it is possible to secure, in order that, owing to the decreased plasticity no strains are produced due to the flow of the clay through the die. The tendency to show auger lamination seems to be reduced by the preheating of the clay. Owing to the decreased drying shrinkage, the die or mold may be made smaller where common brick or other porous ware is to be produced. For vitrified products the gain due to the smaller mold size is slight, since, owing to the increased porosity of the dry clay, the burning shrinkage will be greater.

With reference to the burning of preheated clays it has been found that the combined drying and burning shrinkage, the burning being carried through vitrification, is less than in the case of the normal material. Clays differ in this respect, however. While in one instance the difference in the total volume shrinkages was but $\mathrm{I}$ per cent, in others it was very much greater. In one case the difference amounted to I 2.4 per cent, expressed in terms of the dry volume. ${ }^{13}$

For products to be vitrified the factor of the greater porosity in the dried condition may enter into consideration. Since in vitrification the pore space is more or less gradually closed up, due to the softening of the clay, it is evident that the contraction in the apparent volume of a piece of clay ware must be practically

${ }^{13}$ A. V. Bleininger and F. E. Layman, Trans. Am. Ceramic Society, II, pp. 354-365. 
equivalent to the pore space of the dried material. The extent to which such a volume shrinkage may take place without injury to the structure, distortion, etc., is evidently limited. While, for instance, a brick made from shale, with an initial compact, dense structure may be vitrified without an excessive contraction during burning, a plastic surface clay, of loose structure on being carried to vitrification will suffer a far greater shrinkage, and hence is much more subject to defects brought about by the contraction in volume. If this clay were now to be preheated at a temperature at which its pore-water content is increased decidedly, it is clear that the difficulty referred to would be accentuated. For instance, referring to Fig. I 2 , it is reasonable to suppose that this clay when preheated to $300^{\circ}$ would likely be troublesome in burning it to vitrification. On the other hand, the clay represented by Fig. I4, under the same conditions, would in all probability behave very similarly to its condition in the normal state.

From this it follows that some plastic clays, while they may be corrected as to drying behavior by preheating, might crack or check in burning, due to excessive burning shrinkage. The effect of the preliminary drying thus must be determined for each clay, and in any case the preheating must be carried on at the lowest temperature which suffices to overcome the drying defects. In some cases the admixture of normal and preheated clay might be satisfactory.

In practice the preliminary drying is undoubtedly carried on most efficiently in rotary dryers, such as are now in common use in the Portland-cement industry. The cost of the treatment in well-constructed dryers of this type is estimated to vary from to to I 5 cents per ton of bank clay under the conditions obtaining in the Middle West, including labor and depreciation. This extra cost no doubt is a burden which should not be assumed where the clay can possibly be made to dry satisfactorily by other means, such as the addition of sand, weathering, etc. But where no other material is available and clay products are in demand, owing to lack of timber and stone, or where, as has been found in the case of an Illinois joint clay, ${ }^{13}$ even the addition of sand does not overcome the tendency to crack in drying, the treatment offers a pos- 
sible solution of the difficulty. Five instances are at present known to the writer in which preheating has been found to be the means of overcoming the poor working and drying qualities of certain clays, as has been proved by tests on a large scale.

At the same time it must be remembered that the dry clay can be disintegrated and screened more readily than the clay coming wet from the bank, thus enabling the manufacturer to remove the impurities, such as gravel, limestone, pebbles, and other mineral detritus, which are especially liable to be present in the glacial clays, more cheaply and thoroughly, besides making the operator independent of weather conditions. Also, it is thus possible to produce wares of a higher grade from low-grade material and in districts where other clays are lacking.

\section{SUMMARY}

The plasticity of clays is decreased by heating at temperatures above $100^{\circ} \mathrm{C}$. This change becomes more marked with higher temperatures and is accompanied by reduction of the drying shrinkage upon reworking. According to the nature of the clay, the change proceeds abruptly after reaching a certain temperature or is more or less gradual throughout. A decided alteration seems to occur in most clays between $200^{\circ}$ and $300^{\circ} \mathrm{C}$, as is shown by the granular appearance of the clay and the decrease in the drying shrinkage. The color also becomes darker, and in ferruginous materials assumes a reddish hue.

The purer clays seem to be affected more gradually by this heat treatment.

The rate of drying of the preheated clays does not seem to differ from the rate for the undried clays.

Excessively plastic clays, which dry difficultly and result in loss due to checking and cracking, behave normally in drying after being preheated. The best temperature for this treatment must be determined for each clay, and invariably the lowest possible temperature giving the desired result should be adopted. Some preheated clays seem to release their soluble salts more casily than the normal materials. Such clays are likely to show dryer efflorescence. 
Clays thus treated should be tempered with as little water as possible and require good lubrication.

The cause of the improved drying quality of the preheated clays is to be songht in the increased porosity. It appears that coagulation of the flocculent portion and the fine, nongranular particles of the clay takes place, analogous to the set of certain gels.

The combined drying and burning shrinkage of preheated clays (burnt through vitrification) is less than that of the normal materials. In most cases the drying shrinkage is decreased at the expense of the burning shrinkage, which becomes greater than the normal contraction. In some clays the increased porosity in the dried state may cause the burning shrinkage (if carried through vitrification) to be excessive, in which case the product will show checking or cracking in burning. Such clays, unless their objectionable features in drying can be eliminated by preheating at a low temperature, are not benefited by this treatment.

Preheating offers a possible commercial method for the treatment of excessively plastic clays which can not be worked and dried successfully by other means, subject to the limitations outlined above.

Washington, December 6, I9 IO. 